\title{
Plug-in Hybrid Electric Vehicle Fuel Use Reporting Methods and Results
}

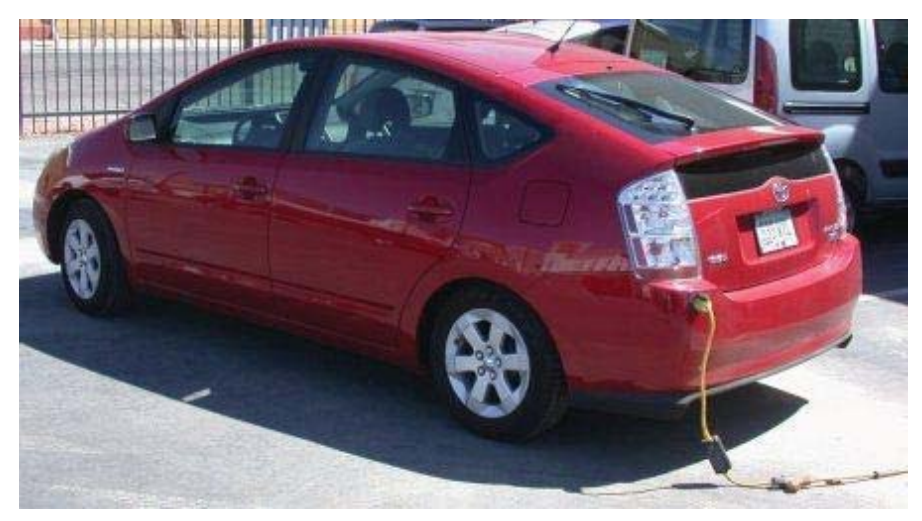

\author{
James E. Francfort \\ Richard B. Carlson \\ Mindy L. Kirkpatrick \\ Matthew G. Shirk \\ John G. Smart \\ Sera E. White
}

July 2009

The Idaho National Laboratory is a U.S. Department of Energy National Laboratory Operated by Battelle Energy Alliance 


\title{
Plug-in Hybrid Electric Vehicle Fuel Use Reporting Methods and Results
}

\author{
James E. Francfort \\ Richard B. Carlson \\ Mindy L. Kirkpatrick \\ Matthew G. Shirk \\ John G. Smart \\ Sera E. White
}

\begin{abstract}
July 2009
Idaho National Laboratory

Transportation Technology Department

Idaho Falls, Idaho 83415
\end{abstract}

Prepared for the

U.S. Department of Energy

Assistant Secretary for Energy Efficiency and Renewable Energy

Under DOE Idaho Operations Office

Contract DE-AC07-05ID14517 


\section{Disclaimers}

This document highlights work sponsored by agencies of the U.S. Government. Neither the U.S. Government nor any agency thereof, nor any of its employees, makes any warranty, express or implied, or assumes any legal liability or responsibility for the accuracy, completeness, or usefulness of any information, apparatus, product, or process disclosed, or represents that its use would not infringe privately owned rights. Reference herein to any specific commercial product, process, or service by trade name, trademark, manufacturer, or otherwise does not necessarily constitute or imply its endorsement, recommendation, or favoring by the U.S. Government or any agency thereof. The views and opinions of authors expressed herein do not necessarily state or reflect those of the U.S. Government or any agency thereof. 


\begin{abstract}
The Plug-in Hybrid Electric Vehicle Fuel Use Reporting Methods and Results report provides real-world test results from plug-in hybrid electric vehicle (PHEV) operations and testing in 21 states and Canada. Examples are given that demonstrate the significant variations operational parameters can have on PHEV petroleum use. In addition to other influences, PHEV miles per gallon results are significantly impacted by driver aggressiveness, cold temperatures, and whether or not the vehicle operator has charged the PHEV battery pack. The U.S.

Department of Energy's Advanced Vehicle Testing Activity (AVTA) has been testing PHEVs for several years. The AVTA (http://avt.inl.gov/), which is part of U.S. Department of Energy's Vehicle Technology Program, also tests other advanced technology vehicles, with 12 million miles of total test vehicle and data collection experience. The Idaho National Laboratory is responsible for conducting the light-duty vehicle testing of PHEVs. Electric Transportation Engineering Corporation also supports AVTA by conducting PHEV and other types of testing. To date, 12 different PHEV models have been tested, with more than 800,000 miles of PHEV operations data collected.
\end{abstract}




\section{EXECUTIVE SUMMARY}

The U.S. Department of Energy's Advanced Vehicle Testing Activity (AVTA) has been testing plug-in hybrid electric vehicles (PHEVs) for several years. The AVTA (http://avt.inl.gov/), which is part of U.S. Department of Energy's Vehicle Technology Program, also tests other advanced technology vehicles, with 12 million miles of total test vehicle and data collection experience. The Idaho National Laboratory is responsible for conducting the light-duty vehicle testing of PHEVs. Electric Transportation Engineering Corporation also supports AVTA by conducting PHEV and other types of testing.

With 177 PHEVs in testing in 21 states and Canada by AVTA's 75 testing partners, AVTA has collected and is analyzing more than 800,000 miles of PHEV operations data for 12 different models of PHEVs. The duel-fuel nature of PHEVs has introduced much discussion and sometimes misunderstanding as to the potential petroleum reduction benefits of PHEVs as measured by miles per gallon (mpg) of gasoline use. This report provides real-world test results from PHEV operations and testing. Examples are given that demonstrate the significant variations of how efficiently PHEVs can operate on petroleum.

High PHEV mpg results are enabled by using electricity from the grid to power the vehicle, thus reducing gasoline consumption. Therefore, PHEV mpg results can be significantly impacted by whether or not the vehicle operator has charged the PHEV battery pack. Driver aggressiveness, air conditioner use, cold ambient temperatures, and other facts also affect PHEV mpg results.

An example of a combination of these impacts is the January 2009 city driving results in charge-sustaining mode when Hymotion Prius conversions averaged $37 \mathrm{mpg}$. The May 2009 result of $69 \mathrm{mpg}$ when the vehicles were operated in charge-depleting mode during highway trips is an $86 \%$ increase in mpg due to trip type, temperature, and whether or not the PHEV battery pack is charged. Another example is baseline testing results that demonstrated well over $100 \mathrm{mpg}$ when the batteries were charged and about $60 \mathrm{mpg}$ when not charged.

As the PHEV and electric drive technologies mature and PHEVs become available from original equipment manufacturers, it is anticipated that these vehicles will be optimized for PHEV operations and high mpg performance. In the near term, PHEV conversions (such as the Hymotion Prius) are providing valuable insight and documentation for PHEV driver impacts, PHEV mpg potential, charging patterns, and charging requirements. While not averaging $100 \mathrm{mpg}$ overall, testing results do demonstrate significant improvements in mpg when the PHEV batteries are at least partially charged throughout an entire trip.

This report demonstrates how real-world PHEV mpg results vary, with documented results ranging from 10 to $400 \mathrm{mpg}$. However, using either number separately or averaging the two $(205 \mathrm{mpg})$ are not accurate representations of PHEV technology. Similarly, reporting a single mpg result can be misleading, especially if done for a single vehicle or group of vehicles that are rarely charged or operated in very cold environments. When discussing mpg results for PHEV technology, a more accurate or representative discussion may want to focus on 
testing results when entire trips are taken in charge-depleting mode (i.e., when the PHEV battery has at least a partial charge in it the entire trip). Results from charge-depleting mode operations are much more representative of PHEV technology. Only reporting the results when the vehicles are operated in charge-sustaining mode basically takes the "plug" out of plug-in hybrid electric vehicle. 


\section{CONTENTS}

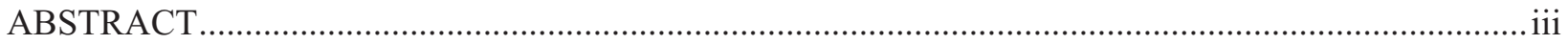

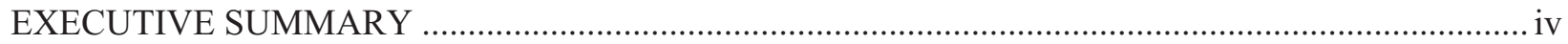

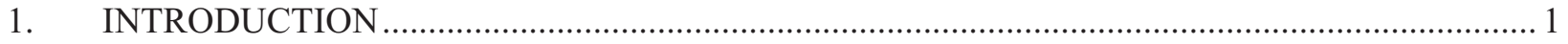

1.1 Plug-In Hybrid Electric Vehicle Operating Modes ..................................................... 2

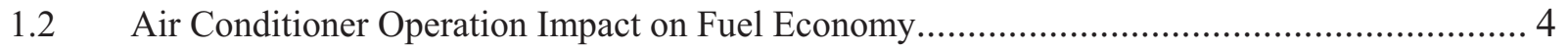

1.3 State-of-Charge Plug-In Hybrid Electric Vehicle Operating Modes.................................... 5

1.4 Real-World Vehicle Operations and Data Collection.................................................. 5

1.5 Plug-In Hybrid Electric Vehicle Fleet Operations Results - March 2008 to May 2009.......... 6

1.6 Plug-In Hybrid Electric Vehicle Fleet Operations Results - January 2009 and May 2009 ...... 6

1.7 Miles per Gallon and Driver Aggressiveness Graphs................................................ 7

$1.8 \quad$ Miles per Gallon in Charge-Depleting Mode Only …............................................... 7

1.9 Miles per Gallon and Operating Mode Trends .................................................... 8

1.10 Plug-In Hybrid Electric Vehicle Testing with Dedicated Drivers.................................... 9

1.11 Baseline Performance Dynamometer Testing .......................................................... 10

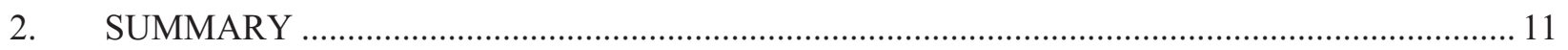

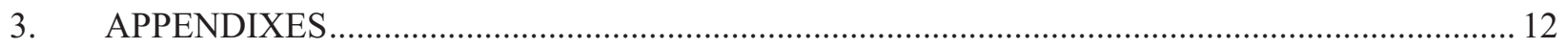

Appendix A - March 2008 to May 2009 Hymotion Prius PHEV Three-Page Summary Fact Sheet ... 14

Appendix B - January 2009 Hymotion Prius PHEV Three-Page Summary Fact Sheet ................... 18

Appendix C - May 2009 Hymotion Prius PHEV Three-Page Summary Fact Sheet........................ 22

Appendix D - Miles per Gallon and Driver Aggressiveness by CD, CS, and Mixed CD/CS Modes... 26

Appendix E - Miles per Gallon and Operating Mode Trends .................................................. 29

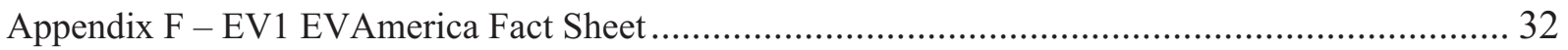




\section{FIGURES}

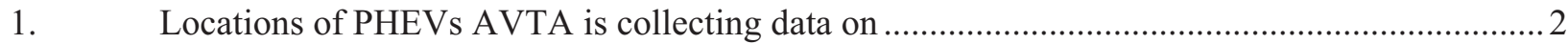

2. Hybrid electric vehicle test results for AVTA baseline performance dynamometer testing with the air conditioning on and off

3. V2Green data logger (black box with cables) being installed inside the left rear of a

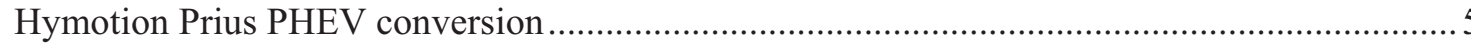

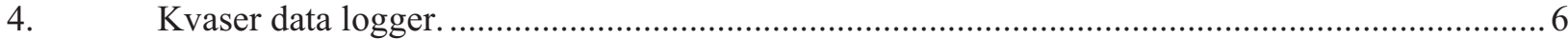

5. Breakdown of miles per gallon results for the 141 Hymotion Prius PHEV conversions driven 22,700 trips and 151,000 miles completely in charge-depleting mode ........................... 8

6. Accelerated testing results for the Hymotion Prius PHEV conversion ..................................9

7. Urban Dynamometer Driving Schedule PHEVAmerica dynamometer test results for the Hymotion Prius PHEV conversion 10 


\section{Plug-in Hybrid Electric Vehicle Fuel Use Reporting Methods and Results}

\section{INTRODUCTION}

Vehicles that feature plug-in hybrid electric vehicle (PHEV) technologies are being tested by the U.S. Department of Energy's (DOE's) Advanced Vehicle Testing Activity (AVTA). The AVTA (http://avt.inl.gov/), which is part of DOE's Vehicle Technology Program, also tests hybrid electric, pure electric, and hydrogen internal combustion engine vehicles that feature advanced energy storage and drive system technologies. This report is intended to provide a high-level discussion of PHEV operating modes and resulting fuel-use and fuel-use reporting methods and issues. The Idaho National Laboratory is responsible for conducting AVTA's lightduty vehicle testing of advanced technology vehicles for DOE. The Electric Transportation Engineering Corporation also supports AVTA by conducting PHEV and other types of testing.

PHEVs are unique in that they can use two different fuels for propulsion (i.e., gasoline and electricity), both of which must come from fueling infrastructure off-board the vehicle. Note that the above sentence states "they can use," not "they use" or "they must use," because today's PHEVs will still operate if vehicle drivers never plug them into the electric grid for recharging. If today's PHEV conversions are not recharged, they operate as a hybrid electric vehicles (HEV) and never achieve higher miles-per-gallon (mpg) results than the HEV they were converted from. Gasoline, biofuel, diesel, electric, fuel cell, and hybrid electric vehicles all must also be fueled from offboard infrastructure, but each vehicle technology only uses one offboard fuel, not two like PHEVs.

This duel-fuel nature of PHEVs has introduced much discussion and sometimes misunderstanding as to the potential petroleum reduction benefits of PHEVs as measured by mpg of gasoline use and electricity use as measured by miles per $\mathrm{kWh}$, Wh per mile, or miles per charge in both electric assist and all-electric propulsion operations. This report is an attempt to explain real-world test results from PHEV fleet operations and testing being conducted by AVTA and its more than 75 PHEV testing partners that are currently operating 177 PHEVs in 21 states and Canada (Figure 1). Examples are given that demonstrate significant variations in PHEV mpg testing results under various operating conditions and testing regimes.

PHEV testing conducted by AVTA is not intended to only test individual PHEV models (12 different PHEV models have been tested to date [different battery technologies in the same base vehicle are considered as separate models]), but to also test the overall concept of PHEVs, including how drivers operate the vehicles, if they charge them, what PHEV driving profiles look like, and what are the major factors that reduce mpg results, which includes aggressive driving, ambient temperatures, accessory use, and driving routes.

It should be noted that the majority of the 177 PHEVs are being operated by fleets that include 40 electric utilities, many governmental agencies, and various types of other private and public fleets. Therefore, the typical driver in the 177 PHEVs is a fleet driver who is generally not responsible for paying for the fuels used in his or her PHEV. Therefore, the economic incentive to achieve the highest mpg of gasoline use and the lowest fuel cost per mile is mostly absent on a personal basis. An exception to this is the PHEV study being led by UCDavis in partnership with AVTA. This group of 13 PHEVs is being driven by 100 private drivers in California on a rotating basis. The 100 PHEV drivers do pay for their own petroleum use; therefore, the final mixture of gasoline and electricity used for propulsion may vary when compared to the fleet drivers. Combined with the high efficiency of PHEV electric drive components relative to the gasoline 
engine, the lower energy cost of electricity will normally result in a much lower cost per mile for electric fuel compared to gasoline

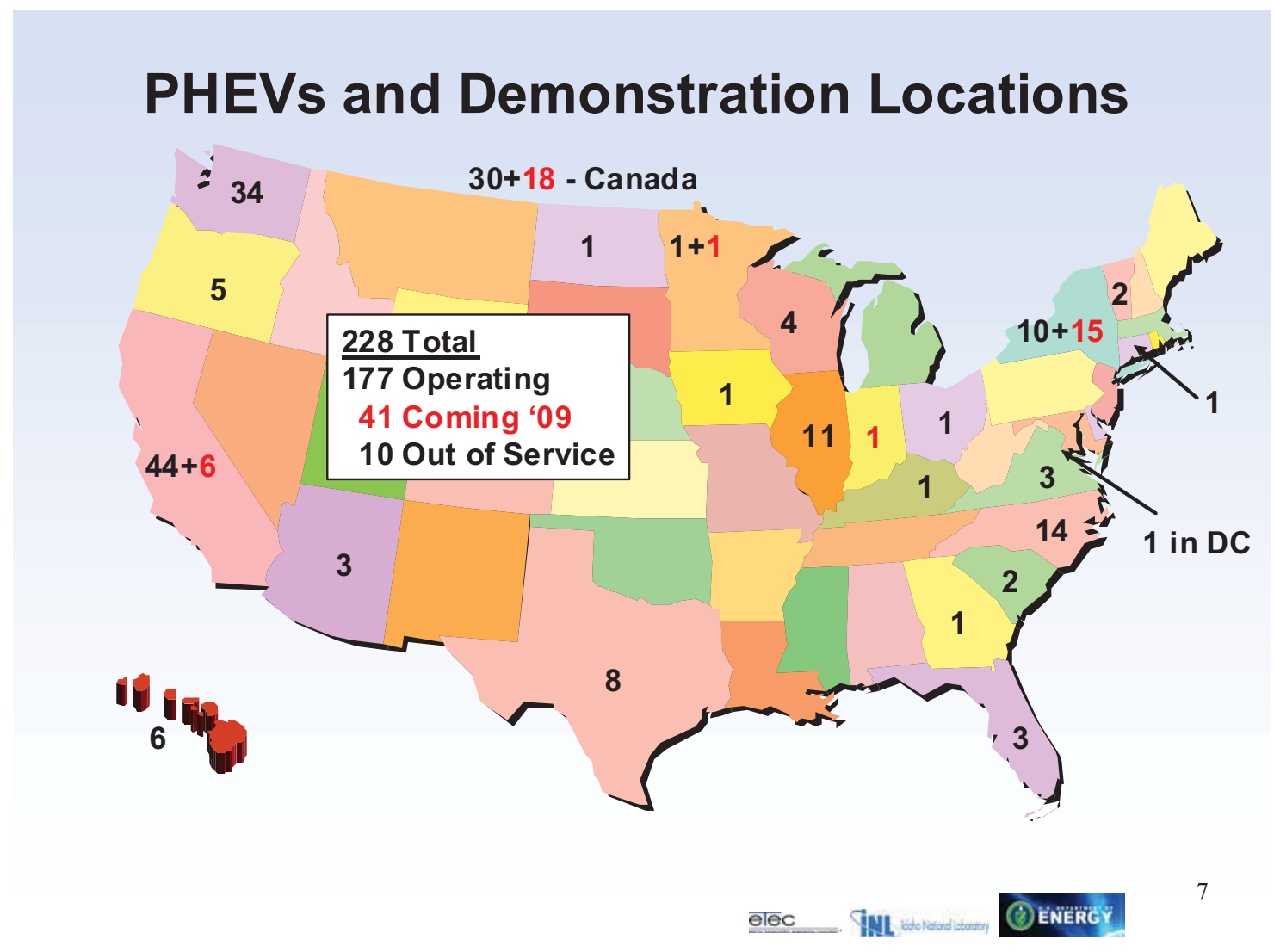

Figure 1. Locations of PHEVs AVTA is collecting data on. The 177 PHEVs are in active use and providing data to AVTA. An additional 10 PHEVs have been removed from testing due to battery replacements, the end of scheduled testing, car crashes, and so forth. Forty-one more PHEVs are being be added to the test fleet during 2009 via previous agreements.

\subsection{Plug-In Hybrid Electric Vehicle Operating Modes}

The duel-fuel scenario of PHEVs allows them to maximize petroleum efficiency by using electricity in various ways to help propel the vehicle in all-electric and electric-assist operations. Depending on PHEV design, a PHEV can be propelled solely by electricity at low speeds (as today's PHEV conversions mostly do) and at medium to high speeds (as future PHEVs will be able to do). In addition, PHEVs provide electric propulsion assistance at the same time the vehicle is propelled by the onboard internal combustion engine when acceleration and other vehicle requirements and control systems allow. On an energy-use basis, electric drive propulsion uses energy several times more efficiently than can currently be achieved with internal combustion engines. The advantage of continuing to use internal combustion engines in today's PHEVs is the very high energy density of gasoline (1 gal of gasoline equals about $35 \mathrm{kWh}$ of electricity), which provides the long driving range of PHEVs. All-electric battery vehicles cannot achieve as long driving ranges because of onboard electric storage limits and the lack of rich recharging infrastructure environments.

Today's PHEVs are mostly comprised of conversion vehicles, with the most commonly converted base vehicle being the Toyota Prius (HEV). The most common PHEV conversion in operation today (as measured in the number of vehicles converted) is the Hymotion Prius PHEV 
conversion. Hymotion (http://www.a123systems.com/hymotion) is owned by A123Systems and the Hymotion conversion uses the A123Systems nanophosphate lithium ion PHEV battery pack in a two-pack design. That is, the Hymotion conversion design keeps the original Toyota HEV nickel metal hydride HEV battery and the second A123Systems PHEV battery is added in a "mule" configuration. The Hymotion mule PHEV battery does not accept recharging from regenerative braking or recharging from the onboard Prius internal combustion engine; it can only be recharged by plugging the vehicle into the electric grid, most commonly via a common 110 -volt electric socket. Some of the other current conversion companies, such as Hybrids Plus (http://www.eetrex.com/) and EnergyCS (http://www.energycs.com/), do remove the original HEV battery pack and replace it with a single PHEV battery that can be partially recharged by regenerative braking and the internal combustion engine. However, even these single PHEV battery pack designs require the PHEV battery to be fully recharged from the electric grid.

It should be noted that most of the automotive original equipment manufacturers are working on various PHEV designs, and some original equipment manufacturers already have limited numbers of PHEVs in small demonstration fleets. These original equipment manufacturers' PHEVs will feature much more optimized PHEV operations and designs, and the expectation is that these upcoming PHEVs will feature significantly improved petroleum use reductions as measured in much higher gasoline mpg results. It should be acknowledged that when the original equipment manufacturers do make PHEVs available to the general public, the manufacturers will likely have to provide 10 or more years and 100,000 or more miles of PHEV battery warranty coverage. Providing such warranty coverage requires much more knowledge about battery life than is currently available. Today's PHEV conversion companies do not provide similar long-term warranty coverage schedules and some of the very smallest conversion companies may not provide any effective warranty coverage at all.

The propulsion system design that the Hymotion Prius PHEV conversions use is mostly the base HEV system designed by Toyota for the Prius, with the exception of the additional PHEV mule battery pack. Unlike a traditional internal combustion engine vehicle, where the gasoline engine must operate to provide propulsion power, the base Toyota Prius HEV design and the addition of the second mule PHEV battery results in several potential PHEV operating modes within a single trip, including the following:

- Internal combustion engine propulsion only

- Internal combustion engine and Toyota HEV battery propulsion

- Internal combustion engine and Hymotion PHEV battery propulsion

- Internal combustion engine and both the HEV and PHEV batteries propulsion

- HEV battery only in all-electric propulsion

- PHEV battery only in all-electric propulsion

- While the vehicle is cruising, braking, or coasting downhill, the internal combustion engine can be rotating with no fuel use, nor electric propulsion.

Because of the many potential operating modes, developing a single test and reporting a single value for mpg, miles per Btu, or miles per kWh is an extremely complex undertaking. In addition, if the PHEV operator chooses to not recharge the PHEV battery pack before a trip, or if charging infrastructure is simply not available for recharging, today's PHEV conversions cannot achieve higher mpg results than the base HEV used for the PHEV conversion. 


\subsection{Air Conditioner Operation Impact on Fuel Economy}

Past dynamometer testing of HEVs by AVTA has quantified decreases in mpg exceeding $20 \%$ (Figure 2) when the air conditioning is used, and cold weather operations have qualified decreases in miles per gallon results of $25 \%$ or more. Just like "regular" non-HEV gasoline vehicles, HEV mpg results are impacted by operating conditions and driving styles. These mpg impacts also occur after the base HEV is converted to a PHEV, and are often very large when mpg results are compared for PHEV operations with a fully discharged PHEV battery pack and vehicle operations with fully charged PHEV battery packs. Because of this gasoline use variability, AVTA reports PHEV mpg results by the three different operating modes discussed in the next section, by city and highway types of driving, and documenting driving aggressiveness impacts on mpg. While PHEV battery state-of-charge operating modes have the largest impacts on mpg results, other mpg impacts AVTA is researching include ambient temperature, accessory utilization (including heaters, defrosters, and air conditioning), driving routes (change in grades), and cold starts.

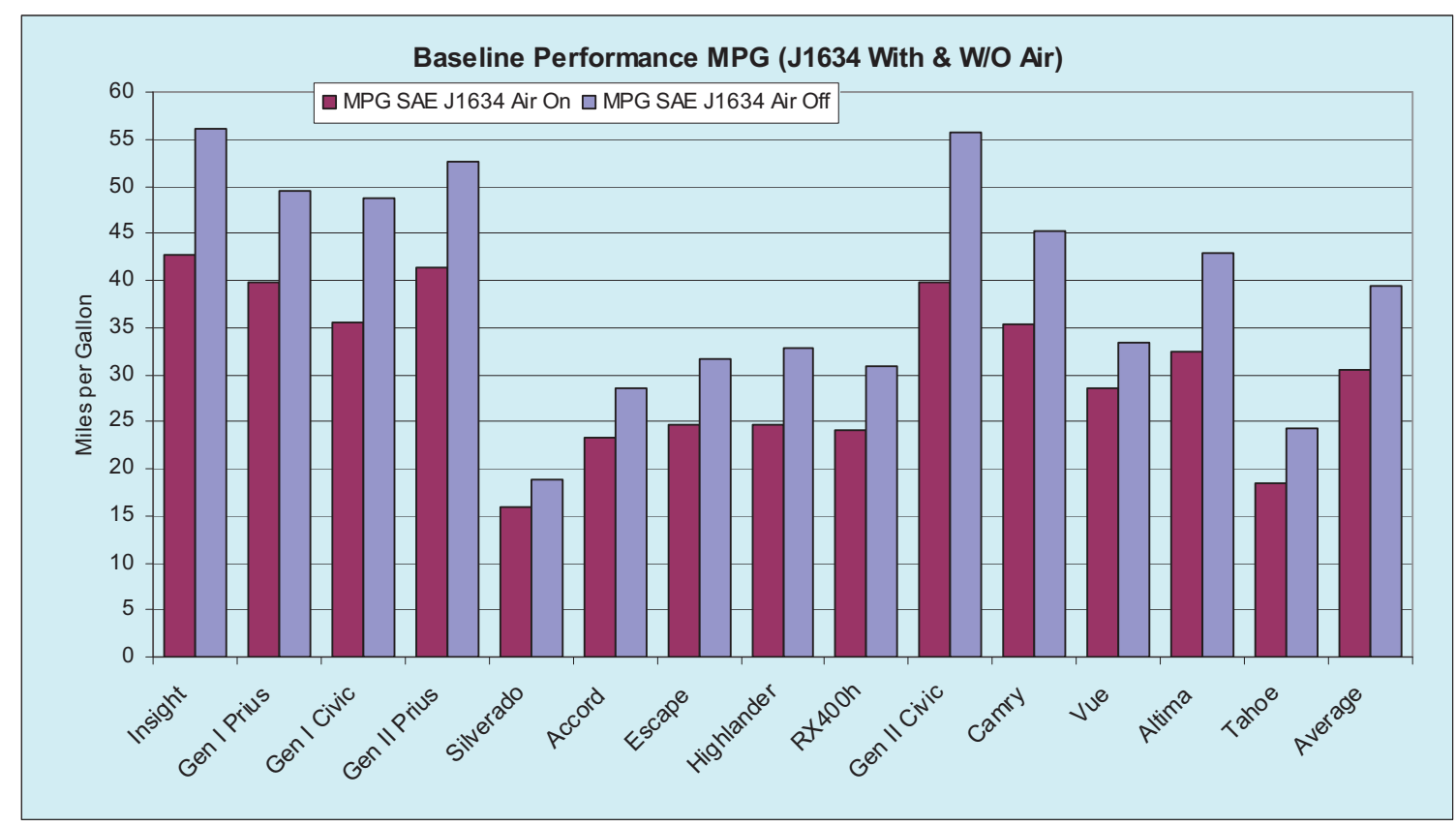

Figure 2. Hybrid electric vehicle test results for AVTA baseline performance dynamometer testing with the air conditioning on and off. See http://avt.inel.gov/hev.shtml for individual results in the baseline performance (HEV America) testing for each HEV model.

Note that because no agreed upon method yet exists for reporting a combined value for gasoline and electricity use, AVTA reports both mpg and kWh separately when appropriate. Industry groups (such as the vehicle manufacturers, the Society of Automotive Engineers, DOE laboratories, and the Environmental Protection Agency) are all working toward a standard test and reporting method for PHEV fuel use. The overall goal of AVTA testing is to support DOE's goal of petroleum reduction and energy security. Therefore, use of electricity for transportation, which can be produced domestically, is considered more desirable than using imported petroleum as a transportation fuel. 


\subsection{State-of-Charge Plug-In Hybrid Electric Vehicle Operating Modes}

State-of-charge operating modes for Hymotion Prius PHEVs are as follows:

Charge-sustaining (CS) mode - from start to finish of a single trip, no electrical energy in the PHEV battery pack is available for electric drive propulsion. Therefore, the battery state-ofcharge is sustained throughout the entire trip. PHEVs are operated in CS mode many times because recharging is not possible between trips, the vehicle operator chooses to not recharge the vehicle, or the vehicle is operated for longer distances or multiple trips than the PHEV battery's capacity is designed for.

Charge-depleting (CD) mode - from start to finish of a single trip, energy is available in the PHEV battery pack for electric assist or all-electric drive propulsion. Therefore, the battery stateof-charge is being depleted during the trip.

Mixed CD/CS mode - there is energy in the battery pack at the start of a single trip, but the PHEV battery is fully depleted before the trip ends.

Electric propulsion is either in the form of all-electric or electric-assist (i.e., the internal combustion engine also is providing propulsion power) propulsion.

\section{$1.4 \quad$ Real-World Vehicle Operations and Data Collection}

AVTA is collecting data on two groups of Hymotion Prius PHEVs. One group of 95 Hymotion Prius PHEVs is equipped with V2Green (a subsidiary of GridPoint; http://www.v2green.com/) data logger systems (Figure 3), and the second group of 46 Hymotion Prius PHEVs is equipped with Kvaser data loggers (Figure 4; http://www.kvaser.com/). The 95 PHEVs with V2Green data loggers have been operated for 423,013 miles, and due to the cellular communications' method used for uploading vehicle data, the data are collected in a very timely manner. Unless noted otherwise, most of the following discussion is limited to the V2Green data collected on the 95 PHEVs. The 46 Kvaser-equipped Hymotion Prius PHEVs have accumulated 188,124 miles, but data collection lags up to several months due to the Kvaser's non-wireless data collection method.

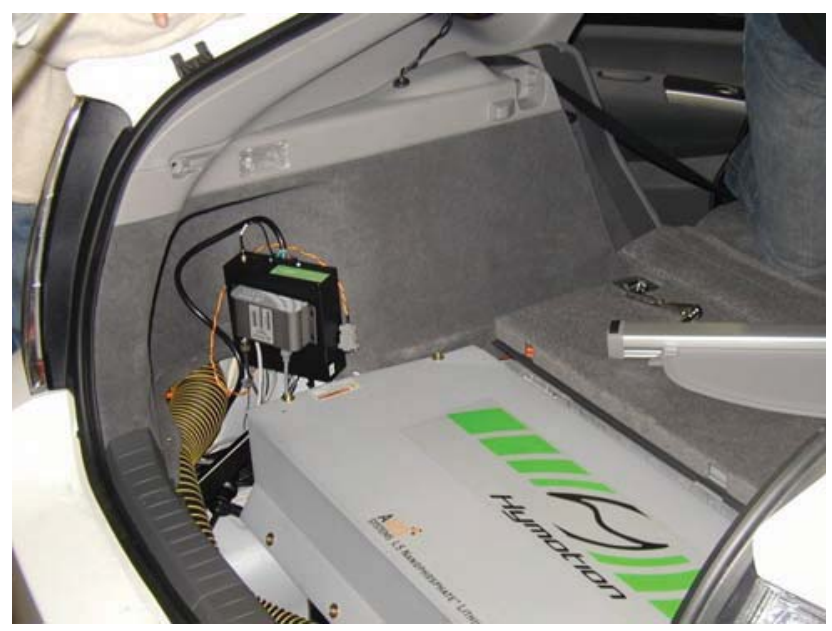

Figure 3. V2Green data logger (black box with cables) being installed inside the left rear of a Hymotion Prius PHEV conversion. The data logger and cellular modem (silver box in front of the V2Green module) is located up and to the left of the Hymotion/A123Systems PHEV battery. 


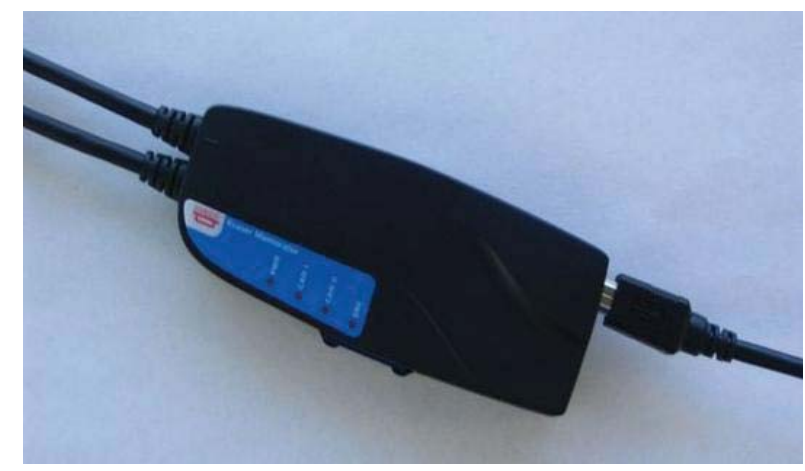

Figure 4. Kvaser data logger.

\subsection{Plug-In Hybrid Electric Vehicle Fleet Operations Results - March 2008 to May 2009}

The AVTA generated a three-page PHEV report for the 95 Hymotion Prius PHEVs with the V2Green data loggers (see Appendix A, first page of the fact sheet), shows an overall mpg result of $50 \mathrm{mpg}$ for all operating modes (i.e., when the vehicles are driven fully charged, partially charged, and not charged at all). It should be understood that the 50-mpg average includes $48 \%$ of the miles driven with no charge in the PHEV battery pack (defined as CS mode), and $27 \%$ of the miles driven in mixed CD/CS mode. The result being that only $25 \%$ of the miles are driven in $\mathrm{CD}$ mode, where the PHEV battery is at least partially charged the entire trip. During CD trips, the 95 PHEVs averaged $63 \mathrm{mpg}$. This is $43 \%$ higher mpg when compared to trips driven with no charge in the PHEV battery (CS mode).

At the top the second page (see Appendix A report), the CD, CS, and mixed CD/CS results are broken down further by city-like and highway-like driving. Trips are assigned "city" or "highway" designations by looking at various statistics, such as average speed and the number of stops per mile. Trips designated "highway" have higher average speeds, fewer stops per mile, and less time accelerating than the "city" trips. Note that the lowest mpg result of 39 mpg is for the trips driven in CS mode and on city routes, while the highest result of $65 \mathrm{mpg}$ is for the CD trips in highway routes. The $65 \mathrm{mpg}$ result is $67 \%$ higher than the $39 \mathrm{mpg}$ result.

The graph in the middle of the second page (Appendix A) titled, "Effect of Driving Aggressiveness on Fuel Economy This Year," provides a summary of the driving style impacts on mpg results. Aggressive driving has been defined as that part of a trip when the vehicle's accelerator pedal (the gas pedal) is depressed $40 \%$ or deeper. The graph shows that when the driver operates the vehicle aggressively only 0 to $20 \%$ ( 0 to 2 on the left axis of the graph) of the time, each trip has an average mpg result of almost $100 \mathrm{mpg}$ (the white vertical space in the bottom blue bar), with some trips getting up to $400 \mathrm{mpg}$.

\subsection{Plug-In Hybrid Electric Vehicle Fleet Operations Results - January 2009 and May 2009}

AVTA generated a three-page report for the 68 Hymotion Prius PHEVs in testing in January 2009 (see Appendix B). This report shows 55 mpg for the trips driven in CD mode (i.e., when the PHEV battery pack has at least a partial charge the entire trip). (Note that this report is only for data collected for the month of January 2009). The 55-mpg result for that month was $31 \%$ higher than the $42 \mathrm{mpg}$ for trips driven in CS mode. Comparing the CD mode and highway type of driving result of $58 \mathrm{mpg}$ and the CS mode and city type of driving result of $37 \mathrm{mpg}$ on the second page of the report (Appendix B), the CD mode and highway driving petroleum mpg result is $57 \%$ higher. 
The May 2009 report (see Appendix C) for the Hymotion Prius PHEVs show CD operation results of $68 \mathrm{mpg}$, which is $51 \%$ higher than the CS operations of $45 \mathrm{mpg}$. The CD results for May 2009 of $68 \mathrm{mpg}$ is 24\% higher than the CD results of $55 \mathrm{mpg}$ for January 2009, most likely due to the warmer operating environment in May 2009.

This comparison can be taken even further if one compares the May $2009 \mathrm{CD}$ mode and highway driving result of 69 miles per gallon to the January 2009 CS mode and city driving result of $37 \mathrm{mpg}$. This is an $86 \%$ increase in mpg due to trip type, temperature, and whether or not the PHEV battery pack is charged.

\subsection{Miles per Gallon and Driver Aggressiveness Graphs}

The three graphs in Appendix D represent 575,000 miles and 45,900 trips of Hymotion Prius PHEV operations for the 141 Hymotion Prius PHEVs with Kvaser and V2Green data loggers. The Appendix D graphs only include trips of a 1-mile or greater distance. In all three graphs, aggressive driving was measured as the percent of time each trip the accelerator pedal (gas pedal) was depressed $40 \%$ or more. In each graph, the left axis goes from 0 up to $80 \%$, and the bottom axis is the mpg for each individual trip.

Figure D-1 shows the mpg impacts from aggressive driving during CD trips. The graph shows that trips driven aggressively about $25 \%$ or less of the time can produce up to or greater than $100 \mathrm{mpg}$, and trips driven aggressively about $30 \%$ of the time can produce up to or greater than 75 mpg. (Section 1.7 breaks down these CD results further).

Figure D-2 shows trips when the PHEV battery pack is at least partially charged at the start of the trip, but completely depleted before the trip end (mixed CD/CS mode). As would be expected, the results are a combination of Figure D-1 and Figure D-3 results, with driver aggressiveness impacting the mpg results. However, Figure D-2 does not have as many high-mpg trip results as Figure D-1 due to the PHEV battery packs not being charged at all at the end of each trip.

Figure D-3 shows trips when the PHEV battery pack is not charged at all (CS mode). The mpg results are about the same as for a "regular" Prius that is operated as an HEV, with mpg results mostly in the 20 to 60 -mpg range. AVTA has conducted accelerated testing of 320,000 miles on two Toyota Prius HEVs and the two vehicles averaged $44 \mathrm{mpg}$. One would normally expect a tighter mpg spread around $44 \mathrm{mpg}$; however, operation of the 141 PHEVs included much more cold weather operations in Canada and the northern United States than was conducted on the two vehicles than averaged $44 \mathrm{mpg}$. While not nearly as big of an impact as in Figures D-1 and D-2, driver aggressiveness does appear to have an impact on the CS mpg results given the slight shift to the right for the less aggressively driven CS trips.

\subsection{Miles per Gallon in Charge-Depleting Mode Only}

Figure 5 is a breakdown of mpg results for the 141 Hymotion Prius PHEV conversions driven 22,700 trips and 151,000 miles exclusively in CD mode. The figure shows the percentage of trips taken and the percentage of miles driven that achieved several bands of mpg results. Results are discussed as follows by mpg group:

- Less than $40 \mathrm{mpg}$ - during $13.2 \%$ of the trips and $5.4 \%$ of the miles driven, the PHEVs in CD mode achieved less than $40 \mathrm{mpg}$. These trips likely had a larger percentage of cold engine starts and were driven shorter distances due to the ratio of trips to miles. The average trip distance for this group of PHEVs was 2.7 miles.

- 40 to less than $60 \mathrm{mpg}$ - during $28.7 \%$ of the trips and $27.8 \%$ of the miles driven, the PHEVs in $\mathrm{CD}$ mode achieved between 40 and less than $60 \mathrm{mpg}$. The average trip distance for this group was 6.4 miles. 
- 60 to less than $80 \mathrm{mpg}$ - during $28.4 \%$ of the trips and $37.7 \%$ of the miles driven, the PHEVs in $\mathrm{CD}$ mode achieved between 60 and less than $80 \mathrm{mpg}$. The average trip distance for this group was 8.8 miles.

- 80 to less than $100 \mathrm{mpg}$ - during $14.4 \%$ of the trips and $16.4 \%$ of the miles driven, the PHEVs in CD mode achieved between 80 and less than $100 \mathrm{mpg}$. The average trip distance for this group was 7.5 miles.

- 100 to less than $150 \mathrm{mpg}$ - during $11.1 \%$ of the trips and $10.2 \%$ of the miles driven, the PHEVs in CD mode achieved between 100 and less than $150 \mathrm{mpg}$. The average trip distance for this group was 6.1 miles.

- Greater than or equal to $150 \mathrm{mpg}$ - during $4.1 \%$ of the trips and $2.6 \%$ of the miles driven, the PHEVs in CD mode achieved 150 mpg or greater. The average trip distance for this group was 4.2 miles.

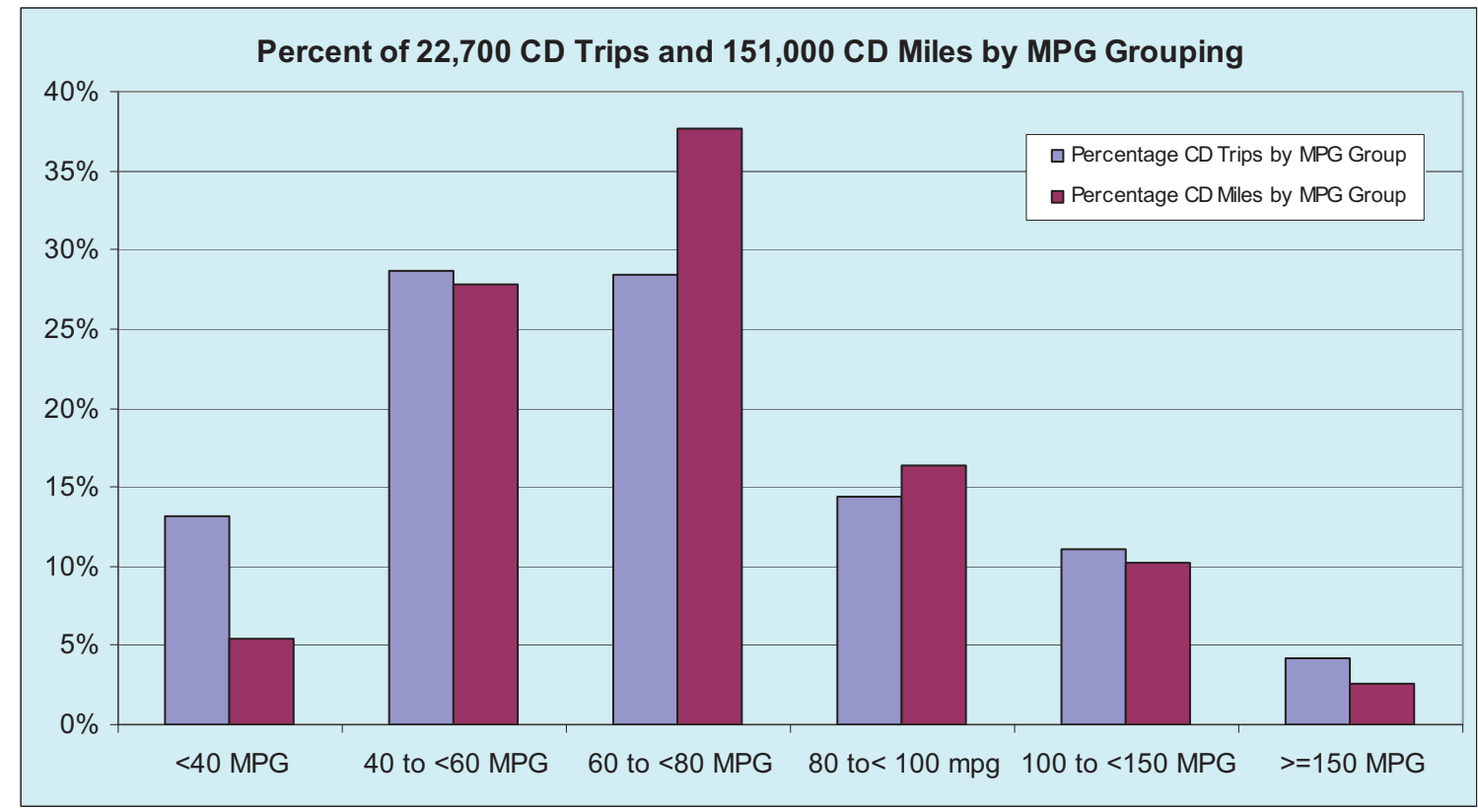

Figure 5. Breakdown of miles per gallon results for the 141 Hymotion Prius PHEV conversions driven 22,700 trips and 151,000 miles completely in charge-depleting mode.

Combining the results for the last two groups show that for $15.3 \%$ of all trips taken and $12.8 \%$ of all miles driven while in CD mode, the 95 PHEVs achieved greater than $100 \mathrm{mpg}$. Combining the results for the last three groups shows that for $29.7 \%$ of all trips taken and $29.1 \%$ of all miles driven while in CD mode the 95 PHEVs achieved 80 or greater mpg.

\section{$1.9 \quad$ Miles per Gallon and Operating Mode Trends}

The three graphs in Appendix E represent monthly numbers of trips, miles driven, and mpg for the 95 PHEVs with the V2Green data loggers for the period from April 2008 through the end of June 2009.

Figure E-1 in Appendix E shows the monthly mpg results for all three (i.e., CD, CS, and mixed $\mathrm{CD} / \mathrm{CS}$ ) operating modes and the combined average mpg results for all three modes. Note the decrease in average mpg results for all operating modes during the winter months of $2008 / 2009$, when colder temperatures likely impacted mpg results compared to the summer of 2008 results. This is especially true for mpg results for CD mode operations, when the results 
went from near $75 \mathrm{mpg}$ in the summer of 2008 to $55 \mathrm{mpg}$ in the coldest winter months. It should be noted that there were only 34 PHEVs with V2Green data loggers in September 2008 compared to 95 in May 2009. The spring of 2009 is demonstrating a return to higher mpg results, but it will be several more months before AVTA can document summer time mpg results.

Figure E-2 shows monthly miles driven by operating mode, with the largest percentage of miles being accumulated in CS mode. About $50 \%$ of all miles were most recently driven in CS mode.

Figure E-3 shows a somewhat opposite result than Figure E-2. It shows that most trips taken by a single operating mode almost every month have been in CD mode, with about $50 \%$ of all trips most recently being taken completely in CD mode.

\subsection{Plug-In Hybrid Electric Vehicle Testing with Dedicated Drivers}

In addition to all PHEV fleet testing and data collection discussed above, AVTA also uses dedicated drivers to test PHEVs on defined routes in the Phoenix, Arizona area. Called accelerated testing, this onroad testing uses combinations, or cycles, of set 10-mile urban (city streets) and highway loops (Figure 6).

Hymotion Prius Gen I - Accelerated Testing
\begin{tabular}{|r|r|r|r|r|r|r|r|r|}
\hline Cycle & Urban & Highway & Charge & Reps & Total & Electricity & \multicolumn{1}{|c|}{ Gasoline } \\
\hline$(\mathrm{mi})$ & $(10 \mathrm{mi})$ & $(10 \mathrm{mi})$ & $(\mathrm{hr})$ & $\mathbf{( N )}$ & $(\mathrm{mi})$ & AC kWh & Gals & MPG \\
\hline 10 & 1 & 0 & 4 & 60 & 600 & 136.33 & 4.81 & 127.2 \\
\hline 20 & 1 & 1 & 8 & 30 & 600 & 122.02 & 5.37 & 115.9 \\
\hline 40 & 4 & 0 & 12 & 15 & 600 & 84.10 & 6.05 & 101.1 \\
\hline 40 & 2 & 2 & 12 & 15 & 600 & 87.22 & 5.78 & 106.9 \\
\hline 40 & 0 & 4 & 12 & 15 & 600 & 79.82 & 8.54 & 73.1 \\
\hline 60 & 2 & 4 & 12 & 10 & 600 & 55.33 & 8.98 & 68.9 \\
\hline 80 & 2 & 6 & 12 & 8 & 640 & 43.99 & 11.36 & 58.3 \\
\hline 100 & 2 & 8 & 12 & 6 & 600 & 35.98 & 8.43 & 73.2 \\
\hline 200 & 2 & 18 & 12 & 3 & 600 & 15.0 & 11.02 & 54.8 \\
\hline Total & 2340 & 3100 & 1404 & 167 & 5,440 & Weighted Average & 79.5 \\
\hline
\end{tabular}

Each total distance slightly greater than 600 and 640 miles. HEV version $=44 \mathrm{mpg}$

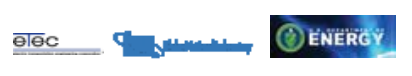

Figure 6. Accelerated testing results for the Hymotion Prius PHEV conversion.

Using the 10-mile cycle in Figure 6 as an example, the dedicated driver operates the vehicle for 10 miles over a defined route and the vehicle is charged for a minimum of 4 hours afterwards. The 10-mile drive and 4 hours of charging is repeated 60 times, achieving a total of 600 miles of driving and 60 charges of at least 4 hours each. The $\mathrm{kWh}$ and gallons of gasoline used are reported, as well as the mpg result.

For the 600 miles of the 10-mile cycle, the Hymotion Prius conversion achieved $127.2 \mathrm{mpg}$. While there is some variability in the number of urban and highway loops that constitute each test cycle, results show that this PHEV's mpg results decrease as cycle distances increase. However, 
for the 2,400 miles of operations over the 10-mile, 20-mile, and two 40-mile cycles, the Hymotion Prius averaged between 101.1 to $127.2 \mathrm{mpg}$. Therefore, this vehicle averaged over $100 \mathrm{mpg}$ for $44 \%$ of the total test miles.

\subsection{Baseline Performance Dynamometer Testing}

AVTA also conducts a series of PHEV tests that are performed on closed test tracks and dynamometers. Testing includes acceleration times and speeds, braking distances, and energy use. Several tests are conducted more than once in CS and CD modes and with the vehicle's air conditioning on and off. Dynamometer testing includes several driving cycles, including the Urban Dynamometer Driving Schedule (UDDS). Figure 7 shows UDDS test results for the Hymotion Prius PHEV. During UDDS testing, the first cycle of a 7.48-mile distance is a cold start for the vehicle (i.e., the vehicle engine has not been operated overnight). The remaining cycles are all warm starts. The first four bars from left to right (bars at cumulative distances of 7.5, 14.9, 22.4 and 29.9 miles) represent UDDS test results when the vehicle was operating in CD mode. Actual testing continues only for two more cycles (bars at cumulative distances of 37.3 and 44.8 miles) when the vehicle is in CS mode.

The red line in Figure 7 shows cumulative AC kWh used and the blue line shows cumulative mpg. Note that the additional UDDS tests were not conducted beyond the first four CD tests and the first two CS tests. Additional distances are plotted to show cumulative mpg results out to 200 miles. The UDDS test results clearly show the comparative contribution that PHEV operations can make to higher mpg results when the vehicle is operated in CD mode.

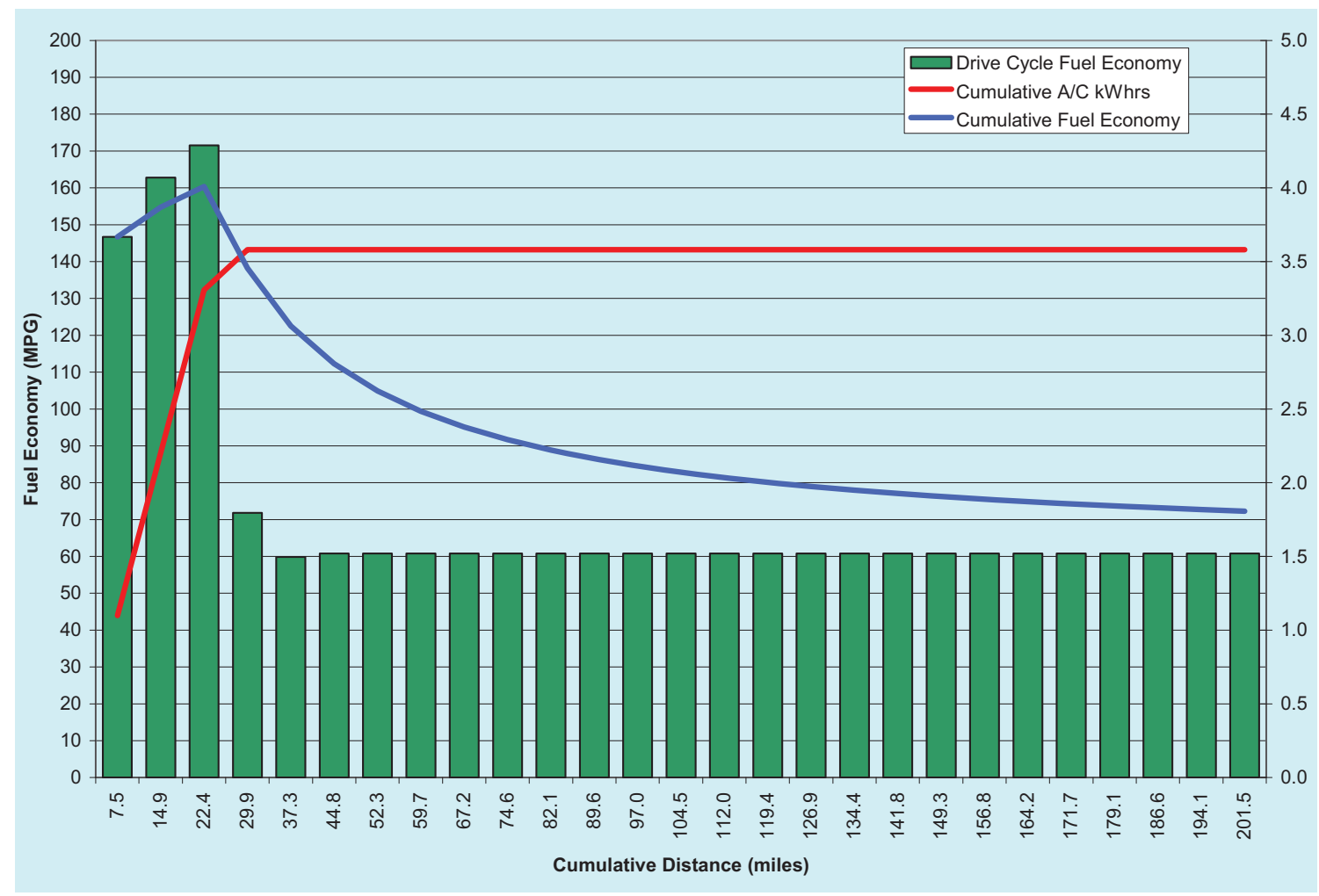

Figure 7. Urban Dynamometer Driving Schedule PHEVAmerica dynamometer test results for the Hymotion Prius PHEV conversion. To view the entire three-page PHEVAmerica baseline performance testing fact sheet, see: http://avt.inel.gov/pdf/phev/toyotaPriusHymotionFact.pdf. 


\section{SUMMARY}

It should be noted that as of May 2009, 18 of the 95 vehicles with the V2Green data loggers are being operated in Canada and cold temperatures have been demonstrated to have a negative impact on PHEV mpg, as well as the mpg achieved by HEVs and "regular" internal combustion engine vehicles most people drive every day. A driver's style or driver's aggressiveness and the type of driving routes (i.e., city versus highway) have been demonstrated to impact PHEV mpg results. Clearly, the largest single impact to mpg results is whether or not the vehicle operator has charged the PHEV battery pack. Each factor has a large influence on fuel economy but the factors are not mutually exclusive. If all factors are present simultaneously, the resulting fuel economy can be significantly less than expected for normal PHEV driving.

An example of a combination of these impacts was mentioned before and is from the January 2009 report, where on the second page the city driving in CS mode averaged $37 \mathrm{mpg}$. The May 2009 report documents $69 \mathrm{mpg}$ when the vehicles are operated in CD mode and highway types of trips; this is an $86 \%$ increase in mpg due to trip type, temperature, and whether or not the PHEV battery pack is charged. Another example is the dynamometer testing results that demonstrate a more than $100 \%$ increase in mpg to more than $140 \mathrm{mpg}$ when the vehicle is operated in CD mode.

Variability of energy use results is true for all electric drive vehicles that have undergone independent testing in various missions and climates. For example, the efficient all-electric General Motors EV1 demonstrated (Appendix F) 221 miles per charge when driven at a constant speed of $45 \mathrm{mph}, 160$ miles per charge when driven at a constant speed of $60 \mathrm{mph}$, and $140 \mathrm{miles}$ per charge when tested on a dynamometer. The 221 miles is $58 \%$ higher than the 140 -mile result. All three of these tests were conducted with professional drivers, in very controlled conditions. Actual fleet operations, often with very nonprofessional drivers, resulted in even greater variability.

In the near term, PHEV conversions (such as the Hymotion Prius PHEV) are providing valuable insight and documentation for driver impacts, environmental and route impacts, mpg potential, charging patterns, and charging requirements. While not averaging $100 \mathrm{mpg}$ overall, testing results do demonstrate significant improvements in mpg when the PHEV batteries are

charged the entire trip. In addition, less aggressive driving styles do demonstrate the potential for high mpg results for PHEV technology, even if they are not fully optimized in today's conversion vehicles.

There have been various reports of low mpg results for PHEVs in various media, and this report demonstrates how real-world PHEV mpg results vary, with documented results ranging from 10 to $400 \mathrm{mpg}$. Using either result separately or averaging the two (205 $\mathrm{mpg}$ ) are not accurate representations of PHEV technology. Similarly, reporting a single mpg result can be extremely misleading, especially if it is done for a single vehicle or group of vehicles that are rarely charged or operated in very cold environments by aggressive drivers.

When discussing mpg results for PHEVs, a more accurate or representative discussion may want to focus on testing results when entire trips are taken in CD mode (i.e., when the PHEV battery has charge in it the entire trip). Results from CD mode operations are much more representative of PHEV technology. When PHEV technology testing results include operations in CS mode, one effectively takes the "plug" out of plug-in hybrid electric vehicles. PHEV operations in CS and mixed CD/CS modes should be documented and reported on to serve two purposes: (1) they document the base vehicle's mpg results without the use of the PHEV battery; and (2) they document the amount of miles driven and trips taken when the PHEV battery is either not fully charged or not charged at all at trip initiation. 
It should be acknowledged that most of the PHEVs that AVTA is testing are conversion PHEVs, not PHEVs designed from the ground up for optimal PHEV performance and petroleum efficiency by the original equipment manufacturers. As PHEV, electric storage, and electric drive technology matures and PHEVs become available from original equipment manufacturers, it is anticipated that these vehicles will be optimized for PHEV operations that include high mpg performance. When additional new PHEVs are available from original equipment manufacturers, AVTA will test them and report on their performance.

The PHEVs reported on in this report are all Hymotion Prius PHEV conversions. This should not be taken as any type of an endorsement one way or the other by AVTA, Idaho National Laboratory, or DOE. The Hymotion Prius PHEV conversion is the single largest PHEV model currently in operations in the United States, representing approximately $75 \%$ or more of all PHEVs in operation. While AVTA is performing testing on many more PHEV models, the Hymotion Prius is the PHEV with the most data loggers installed; therefore, it was chosen as the example to use in discussing PHEV technology fuel use and operations. The other PHEV conversion models AVTA is documenting also display similar variability in fuel use where driver behavior, temperatures, and battery charge status impact vehicle performance.

\section{APPENDIXES}

Appendix A, March 2008 to May 2009 Hymotion Prius PHEV Three-Page Summary Fact Sheet

Appendix B, January 2009 Hymotion Prius PHEV Three-Page Summary Fact Sheet

Appendix C, May 2009 Hymotion Prius PHEV Three-Page Summary Fact Sheet

Appendix D, Miles per Gallon and Driver Aggressiveness by CD, CS, and Mixed CD/CS Modes

Appendix E, Miles per Gallon and Operating Mode Trends 
Appendix A

March 2008 to May 2009 Hymotion Prius PHEV Three-Page Summary Fact Sheet 


\section{Appendix A - March 2008 to May 2009 Hymotion Prius PHEV Three-Page Summary Fact Sheet}

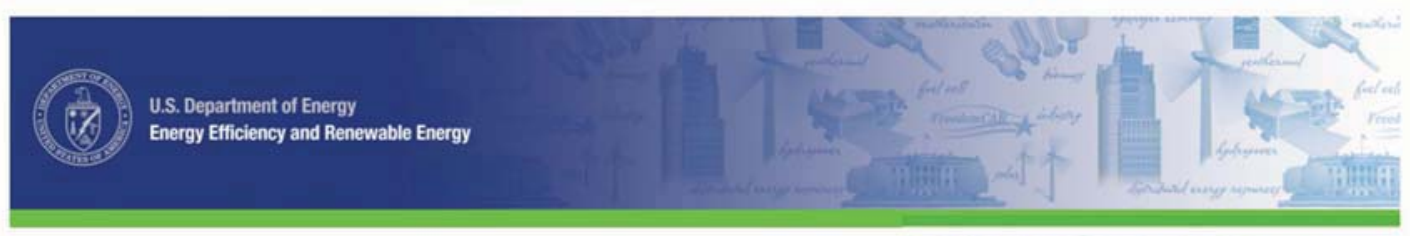

North American PHEV Demonstration

Fleet Summary Report - Hymotion Prius (V2Green data logger) Number of vehicles:

95

Reporting Period: $\quad$ Mar 08 - May 09

All Trips Combined

\begin{tabular}{lr}
\hline Overall gasoline fuel economy $(\mathrm{mpg})$ & 50 \\
\hline Total number of trips & 44304 \\
\hline Total distance traveled $(\mathrm{mi})$ & 423013 \\
\hline
\end{tabular}

Trips in Charge Depleting (CD) mode *

\begin{tabular}{lc|}
\hline Gasoline fuel economy (mpg) & 63 \\
\hline Number of trips & 23010 \\
\hline Percent of trips city / highway & $84.50 \%$ / $15.50 \%$ \\
\hline Distance traveled (mi) & 106267 \\
\hline Percent of total distance traveled & $25.12 \%$ \\
\hline
\end{tabular}

Trips in combined Charge Depleting and Charge Sustaining (CD/CS) modes**

Gasoline fuel economy (mpg)

Number of trips

53

Percent of trips city / highway

Distance traveled (mi)

$48.40 \%$ / $51.60 \%$

Percent of total distance traveled

113555

$26.84 \%$

Trips in Charge Sustaining (CS) mode***

\begin{tabular}{lc|}
\hline Gasoline fuel economy (mpg) & 44 \\
\hline Number of trips & 16532 \\
\hline Percent of trips city / highway & $68.30 \% / 31.70 \%$ \\
\hline Distance traveled (mi) & 203194 \\
\hline Percent of total distance traveled & $48.04 \%$ \\
\hline
\end{tabular}

Number of trips when the plug-in battery pack was turned off by the vehicle operator ${ }^{n}$

1725

Distance traveled with plug-in battery pack turned off $(\mathrm{mi})^{\wedge}$

\section{Vehicle Technologies Program}

Date range of data received:

$4 / 18 / 2008$ to $5 / 31 / 2009$

Number of days the vehicles were driven: 365
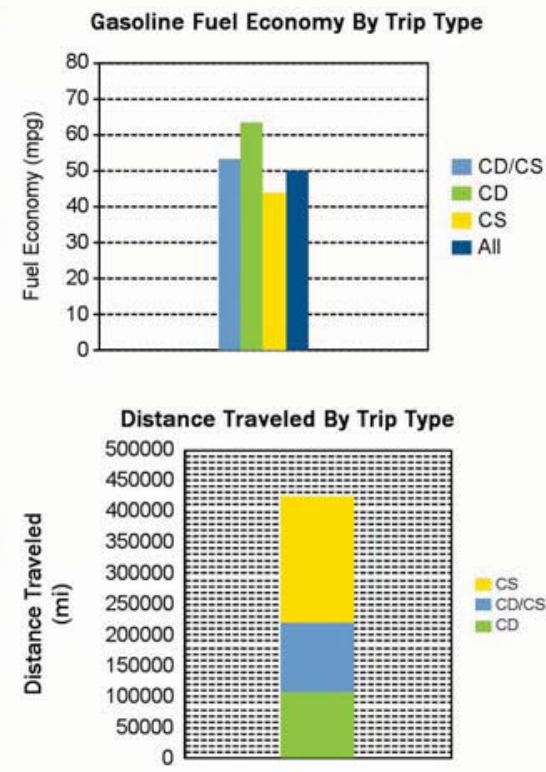

Miles Logged by Month This Year

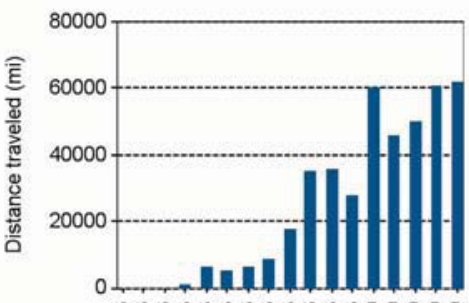

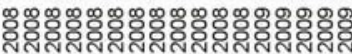

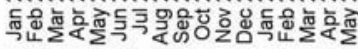

- Trips when the plug-in battery pack charge is depleted to propel the vehicle throughout entire trip

-. Trips when the plug-in battery pack is depleted to propel the vehicle for a portion of the trip, but is fully depleted prior to the end of the trip

... Trips when the plug-in battery pack is not used to propel the vehicle - etther the plug-in battery is fully depleted before the beginning of the trip, $\propto$ the plug-in battery pack is turned off

A "Number of trips wath plug-in battery pack turned off by the vehicle operator" is a subset of number of trips in combined CD/CS and CS mode

An "Distance traveled with plug-in battery pack turned off" is a subset of distance traveled in combineod CD/CS and CS modes 
Percent of miles in electric-only mode

$30.00 \% \quad 8.00 \%$

Average trip aggressiveness (on scale $0-10$ )

$1.5 \quad 1.5$

Average trip distance (mi)

Trips in combined Charge Depleting and Charge Sustaining (CD/CS) modes

\begin{tabular}{l|r|r|}
\hline Gasoline fuel economy (mpg) & 57 & 53 \\
\hline Percent of miles in electric-only mode & $24.00 \%$ & $5.00 \%$ \\
\hline Average trip aggressiveness (on scale $0-10$ ) & 1.8 & 1.5 \\
\hline Average trip distance (mi) & 8.0 & 38.7 \\
\hline Trips in Charge Sustaining (CS) mode & 39 & 45 \\
\hline Gasoline fuel economy (mpg) & $20.00 \%$ & $4.00 \%$ \\
\hline Percent of miles in electric-only mode & 1.6 & 1.6 \\
\hline Average trip aggressiveness (on scale 0 - 10) & 3.8 & 30.7 \\
\hline Average trip distance (mi) & & \\
\hline
\end{tabular}

Effect Of Driving Aggressiveness on Fuel Economy This Year

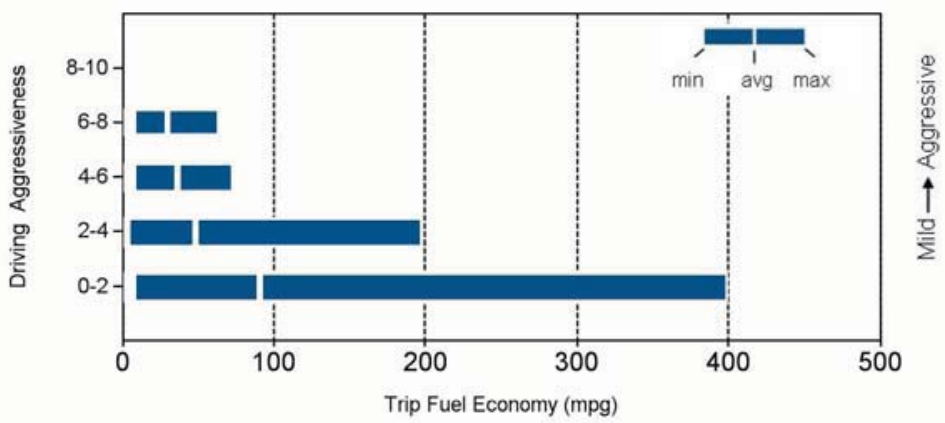

Aggressiveness factor is based on accelerator pedal position. The more time spent during a trip at higher accelerator pedal position, the higher the trip aggressiveness.

Trip Fuel Economy Distribution By Trip Type

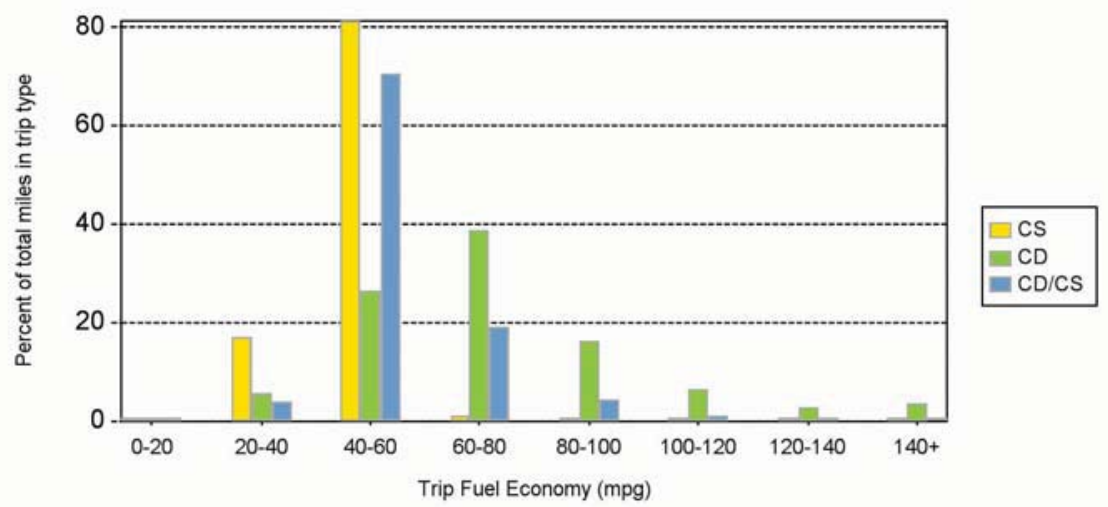


Plug-in charging

Average number of charging events per vehicle per month when driven 16

Average number of charging events per vehicle per day when vehicle driven

1.2

Average distance between charging events

40.2

Average number of trips between charging events

Average duration of charging event (hr) *

18.9

Average energy per charging event ( $\mathrm{AC} \mathrm{KWh)}$

2.6

Average charging energy per vehicle per month ( $\mathrm{AC} \mathrm{kWh)}$

42.3

Total number of charging events

10523

Total charging energy ( $\mathrm{AC} \mathrm{kWh)}$

27124

Time of Day When Driving

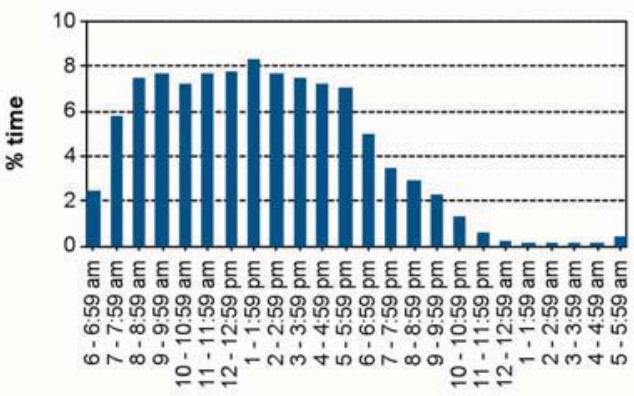

Time of Day When Charging

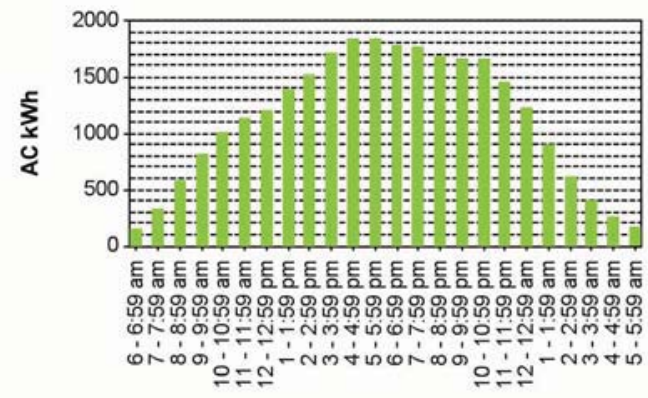

Time at the Start of Charging Events

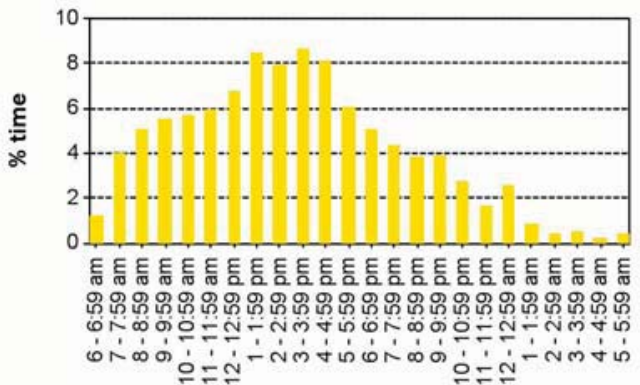

- Average duration of charging event is the average length of time per charging event when the vehicle was plugged into the electrical grid. Electrical energy was not necessarily drawn during the entire period when the vehicle was plugged in. 
Appendix B

January 2009 Hymotion Prius PHEV Three-Page Summary Fact Sheet 


\section{Appendix B - January 2009 Hymotion Prius PHEV Three-Page Summary Fact Sheet}

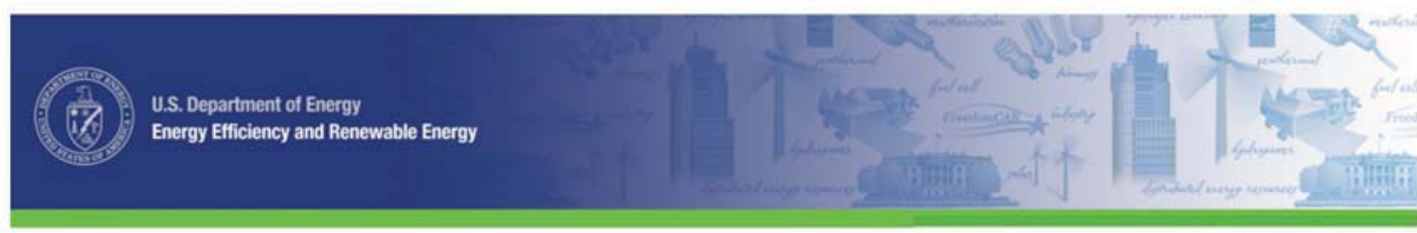

\section{North American PHEV Demonstration}

Fleet Summary Report - Hymotion Prius (V2Green data logger) Number of vehicles:

68

Reporting Period: January 2009

All Trips Combined

\begin{tabular}{lr}
\hline Overall gasoline fuel economy $(\mathrm{mpg})$ & 47 \\
\hline Total number of trips & 5791 \\
\hline Total distance traveled $(\mathrm{mi})$ & 60007
\end{tabular}

Trips in Charge Depleting (CD) mode *

Gasoline fuel economy ( $\mathrm{mpg}$ )

Number of trips

Percent of trips city / highway

Distance traveled (mi)

Percent of total distance traveled

Trips in combined Charge Depleting and Charge Sustaining (CD/CS) modes**

Gasoline fuel economy ( $\mathrm{mpg}$ )

Number of trips

50

Percent of trips city / highway

629

Distance traveled (mi)

$43.70 \%$ / $56.30 \%$

Percent of total distance traveled

$25.52 \%$

4977

$24.96 \%$

modes**
0
$56.30 \%$
2
$52 \%$

Trips in Charge Sustaining (CS) mode ${ }^{* * *}$

Gasoline fuel economy (mpg)

Number of trips

Percent of trips city / highway

Distance traveled (mi)

Percent of total distance traveled
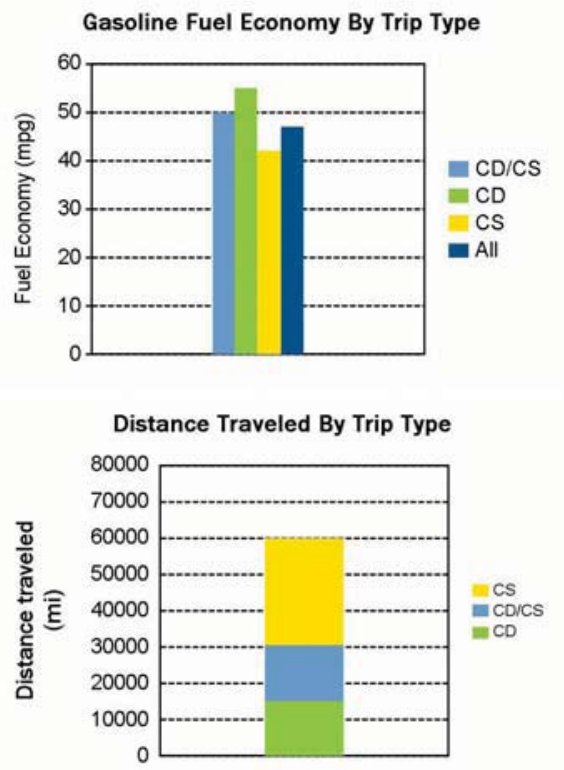

Vehicle Technologies Program

Date range of data received:
$1 / 1 / 2009$
to $1 / 31 / 2009$

Number of days the vehicles were driven: 31

Gasoline Fuel Economy By Trip Type

Number of trips when the plug-in battery pack

was turned off by the vehicle operator ${ }^{\wedge}$

turned off $(\mathrm{mi})^{\wedge \wedge}$

- Trips when the plug-in battery pack charge is depeleted to propel the vehicle throughout entire trip

- Trips when the plug-in battery pack is depleted to propel the vehicle for a portion of the trip, but is fully depleted prior to the end of the trip

... Trips when the plug-in battery pack is not used to propel the vehicle - either the plug-in battery is fully depleted before the beginning of the trip, or the plug-in battery pack is turned off

n Number of trips with plug-in battery pack turned off by the vehicle operator" is a subset of number of trips in combined CD/CS and CS mode

An 'Distance traveled with plug-in battery pack turned off' is a subset of distance traveled in combinecd CD/CD and CS modes 


\begin{tabular}{l|r|r|r|}
\hline Trips in Charge Depleting (CD) mode & City & Highway \\
\hline Gasoline fuel economy (mpg) & 52 & 58 \\
\hline Percent of miles in electric-only mode & $21.00 \%$ & $5.00 \%$ \\
\hline Average trip aggressiveness (on scale 0 - 10) & 1.9 & 2.0 \\
\hline Average trip distance (mi) & 2.9 & 14.7 \\
\hline Trips in combined Charge Depleting and Charge Sustaining (CD/CS) modes & 50 & 50 \\
\hline Gasoline fuel economy (mpg) & $20.00 \%$ & $4.00 \%$ \\
\hline Percent of miles in electric-only mode & 2.2 & 1.7 \\
\hline Average trip aggressiveness (on scale 0 - 10) & 7.5 & 37.4 \\
\hline Average trip distance (mi) & 37 & 44 \\
\hline Trips in Charge Sustaining (CS) mode & $17.00 \%$ & $4.00 \%$ \\
\hline Gasoline fuel economy (mpg) & 1.8 & 1.8 \\
\hline Percent of miles in electric-only mode & 3.4 & 29.5 \\
\hline Average trip aggressiveness (on scale 0 - 10) & & \\
\hline Average trip distance (mi) & & \\
\hline
\end{tabular}

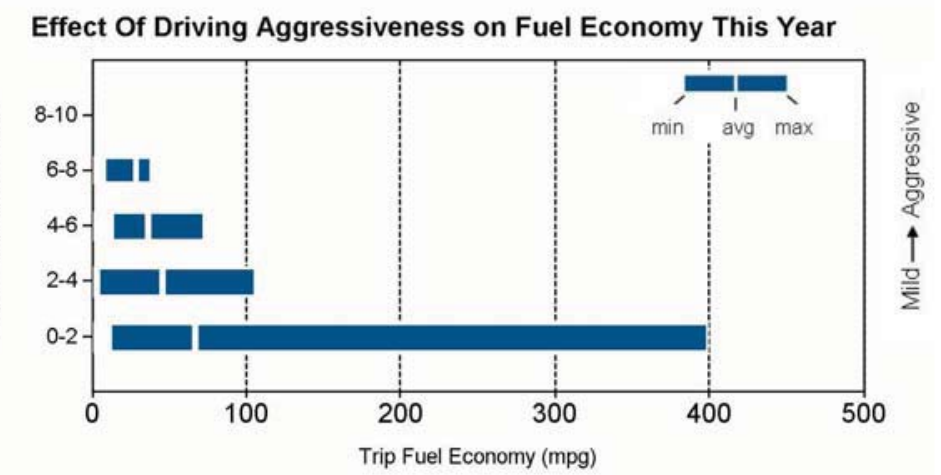

Aggressiveness factor is based on accelerator pedal position. The more time spent during a trip at higher accelerator pedal position, the higher the trip agressiveness.

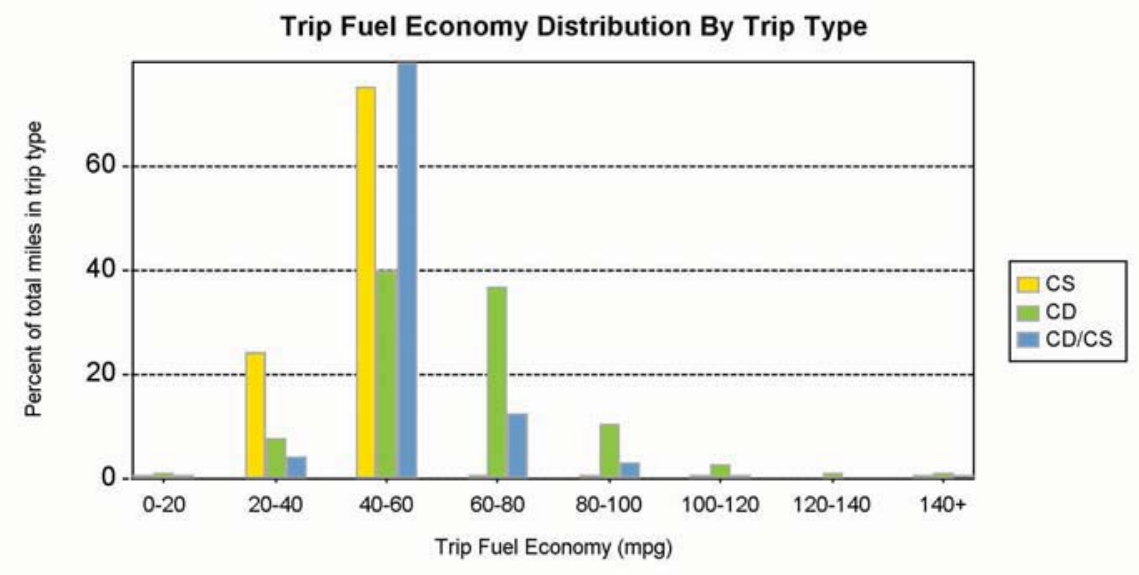


Average number of charging events per vehicle per month when driven

Average number of charging events per vehicle per day when vehicle driven

Average distance between charging events

45.8

Average number of trips between charging events

4.4

Average duration of charging event (hr) *

Average energy per charging event ( $A C \mathrm{kWh}$ )

2.6

Average charging energy per vehicle per month ( $\mathrm{AC} \mathrm{kWh}$ )

51.2

Total number of charging events

1309

Total charging energy $(\mathrm{AC} \mathrm{kWh})$

3434

Time of Day When Driving

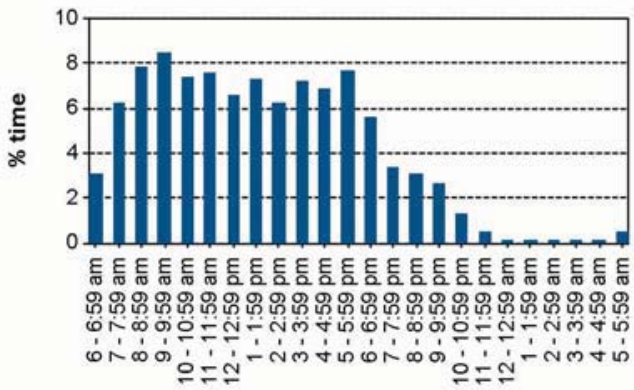

Time of Day When Charging

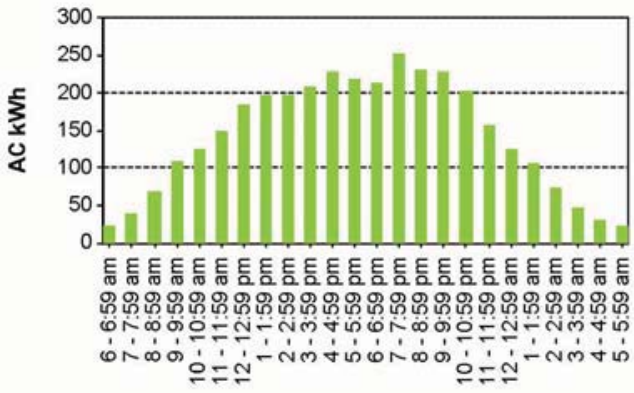

Time at the Start of Charging Events

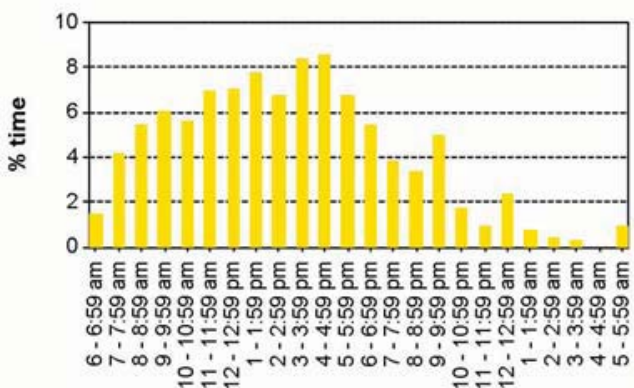

-Average duration of charging event is the average length of time per charging event when the vehicle was plugged into the electrical grid. Electrical energy was not necessarily drawn during the entire period when the vehicle was plugged in. 
Appendix C

May 2008 to May 2009 Hymotion Prius PHEV Three-Page Summary Fact Sheet 


\section{Appendix C - May 2009 Hymotion Prius PHEV Three-Page Summary Fact Sheet}

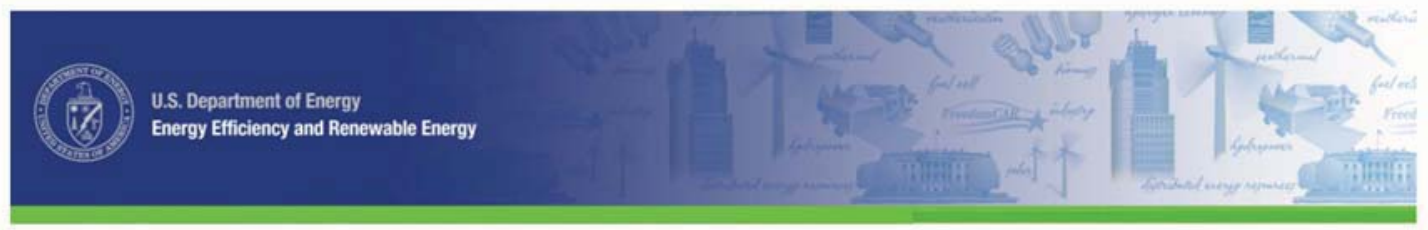

\section{North American PHEV Demonstration}

Fleet Summary Report - Hymotion Prius (V2Green data logger) Number of vehicles:

92

Reporting Period: May 2009

All Trips Combined

\begin{tabular}{lc}
\hline Overall gasoline fuel economy (mpg) & 52 \\
\hline Total number of trips & 6894 \\
\hline Total distance traveled (mi) & 62248 \\
\hline & \\
\hline Trips in Charge Depleting (CD) mode * & 68 \\
\hline Gasoline fuel economy (mpg) & 3685 \\
\hline Number of trips & $86.90 \% / 13.10 \%$ \\
\hline Percent of trips city / highway & 15315 \\
\hline Distance traveled (mi) & $24.60 \%$ \\
\hline Percent of total distance traveled &
\end{tabular}

Trips in combined Charge Depleting and Charge Sustaining (CD/CS) modes**

\begin{tabular}{lc}
\hline Gasoline fuel economy (mpg) & 58 \\
\hline Number of trips & 747 \\
\hline Percent of trips city / highway & $54.90 \% / 45.10 \%$ \\
\hline Distance traveled (mi) & 15214 \\
Percent of total distance traveled & $24.44 \%$
\end{tabular}

Trips in Charge Sustaining (CS) mode***

\begin{tabular}{lc}
\hline Gasoline fuel economy (mpg) & 45 \\
\hline Number of trips & 2462 \\
\hline Percent of trips city / highway & $69.90 \% / 30.10 \%$ \\
\hline Distance traveled (mi) & 31719 \\
\hline Percent of total distance traveled & $50.96 \%$
\end{tabular}

Number of trips when the plug-in battery pack was turned off by the vehicle operator Distance traveled with plug-in battery pack turned off $(\mathrm{mi})^{\wedge \wedge}$
Vehicle Technologies Program

Date range of data received:

$5 / 1 / 2009$ to $5 / 31 / 2009$

Number of days the vehicles were driven: 31
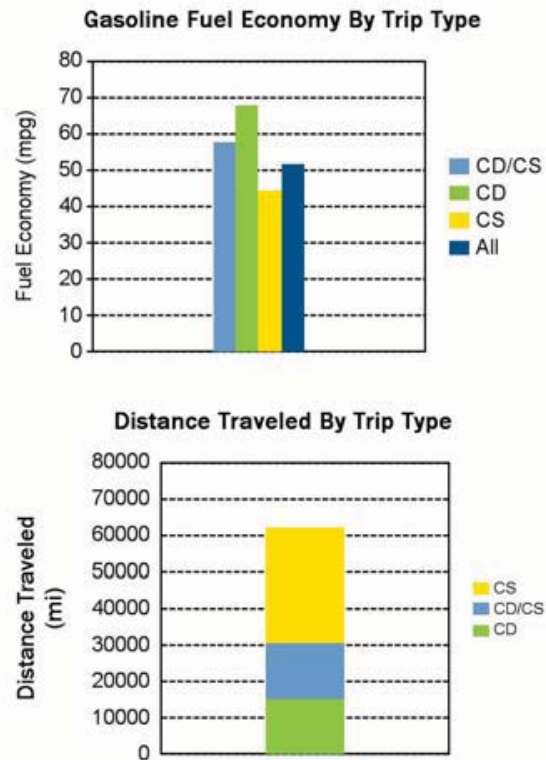

Miles Logged by Month This Year

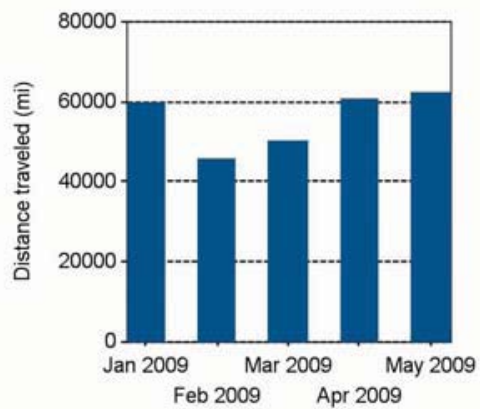

- Trips when the plug-in battery pack charge is depleted to propel the vehicle throughout entire trip

- Trips when the plug-in battery pack is depleted to propel the vehicle for a portion of the trip, but is fully depleted prior to the end of the tip

-.. Trips when the plug-in battery pack is not used to propel the vehicle - eather the plug-in battery is fully depleted before the beginning of the trip, $\alpha$ the plug-in battery pack is turned off

A Number of trips with plug-in battery pack turned off by the vehicle operator" is a subset of number of trips in combined CD/CS and CS mode

$\wedge \wedge$ "Distance traveled with plug-in battery pack turned off' is a subset of distance traveled in combineod CD/CS and CS modes 


\begin{tabular}{|c|c|c|}
\hline Trips in Charge Depleting (CD) mode & City & Highway \\
\hline Gasoline fuel economy (mpg) & 67 & 69 \\
\hline Percent of miles in electric-only mode & $35.00 \%$ & $9.00 \%$ \\
\hline Average trip aggressiveness (on scale $0-10$ ) & 1.4 & 1.5 \\
\hline Average trip distance $(\mathrm{mi})$ & 2.7 & 13.7 \\
\hline \multicolumn{3}{|c|}{ Trips in combined Charge Depleting and Charge Sustaining (CD/CS) modes } \\
\hline Gasoline fuel economy (mpg) & 64 & 56 \\
\hline Percent of miles in electric-only mode & $30.00 \%$ & $6.00 \%$ \\
\hline Average trip aggressiveness (on scale $0-10$ ) & 1.7 & 1.5 \\
\hline Average trip distance $(\mathrm{mi})$ & 8.5 & 34.8 \\
\hline \multicolumn{3}{|l|}{ Trips in Charge Sustaining (CS) mode } \\
\hline Gasoline fuel economy (mpg) & 40 & 46 \\
\hline Percent of miles in electric-only mode & $22.00 \%$ & $4.00 \%$ \\
\hline Average trip aggressiveness (on scale $0-10$ ) & 1.5 & 1.6 \\
\hline Average trip distance (mi) & 3.8 & 34.1 \\
\hline
\end{tabular}

\section{Effect Of Driving Aggressiveness on Fuel Economy This Year}

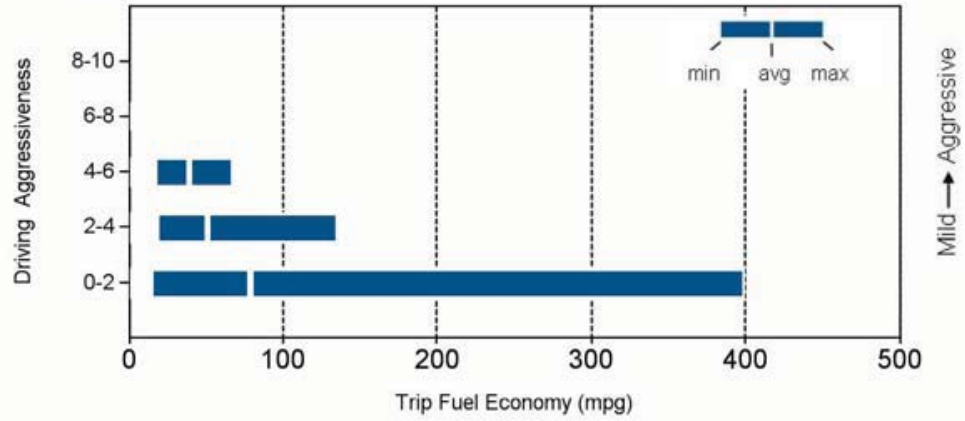

Aggressiveness factor is based on accelerator pedal position. The more time spent during a trip at higher accelerator pedal position, the higher the trip aggressiveness.

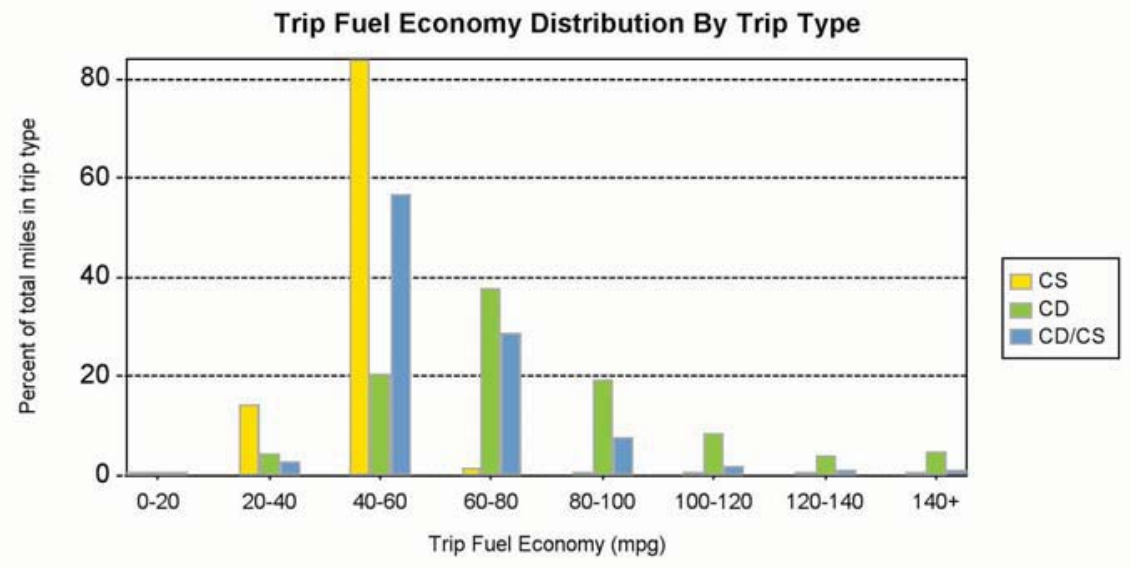


Average number of charging events per vehicle per month when driven

Average number of charging events per vehicle per day when vehicle driven

1.1

Average distance between charging events

40.0

Average number of trips between charging events

4.4

Average duration of charging event (hr) *

20.2

Average energy per charging event ( $\mathrm{AC} \mathrm{kWh}$ )

Average charging energy per vehicle per month ( $\mathrm{AC}$ kWh)

44.6

Total number of charging events

1557

Total charging energy ( $\mathrm{AC} \mathrm{kWh)}$

4062

Time of Day When Driving

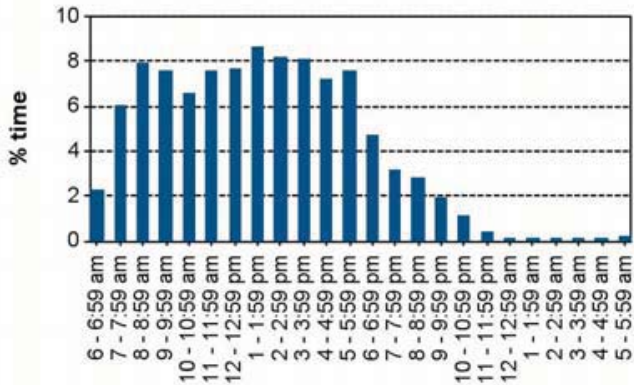

Time of Day When Charging

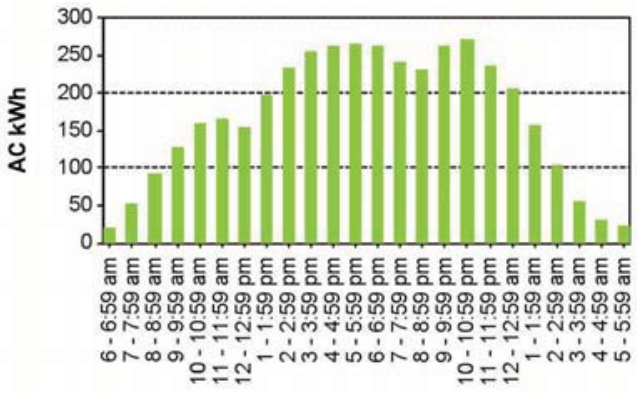

Time at the Start of Charging Events

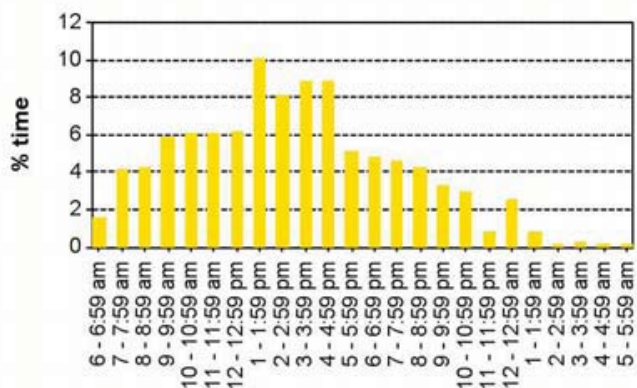

-Average duration of charging event is the average length of time per charging event when the vehicle was plugged into the electrical grid. Electrical energy was not necessarily drawn during the entire period when the vehicle was plugged in. 
Appendix D

Miles per Gallon and Driver Aggressiveness by CD, CS, and Mixed CD/CS Modes 


\section{Appendix D - Miles per Gallon and Driver Aggressiveness by CD, CS, and Mixed CD/CS Modes}

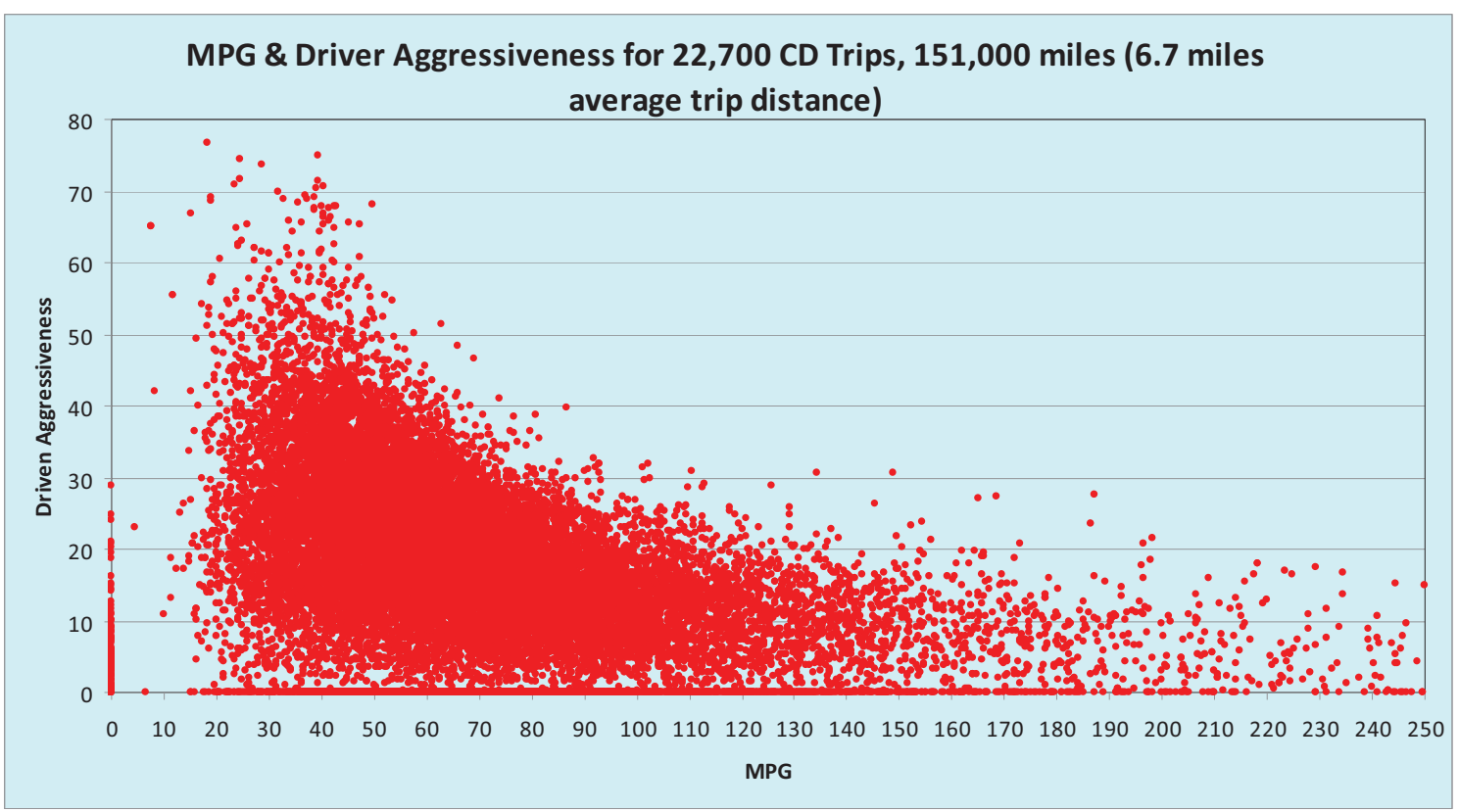

Figure D-1. Driver aggressiveness impacts on mpg for 22,700 trips driven 151,000 miles in charge-depleting mode for 141 Hymotion Prius PHEV conversions. The few 0 mpg results in the graph along the left axis are for trips in all-electric mode.

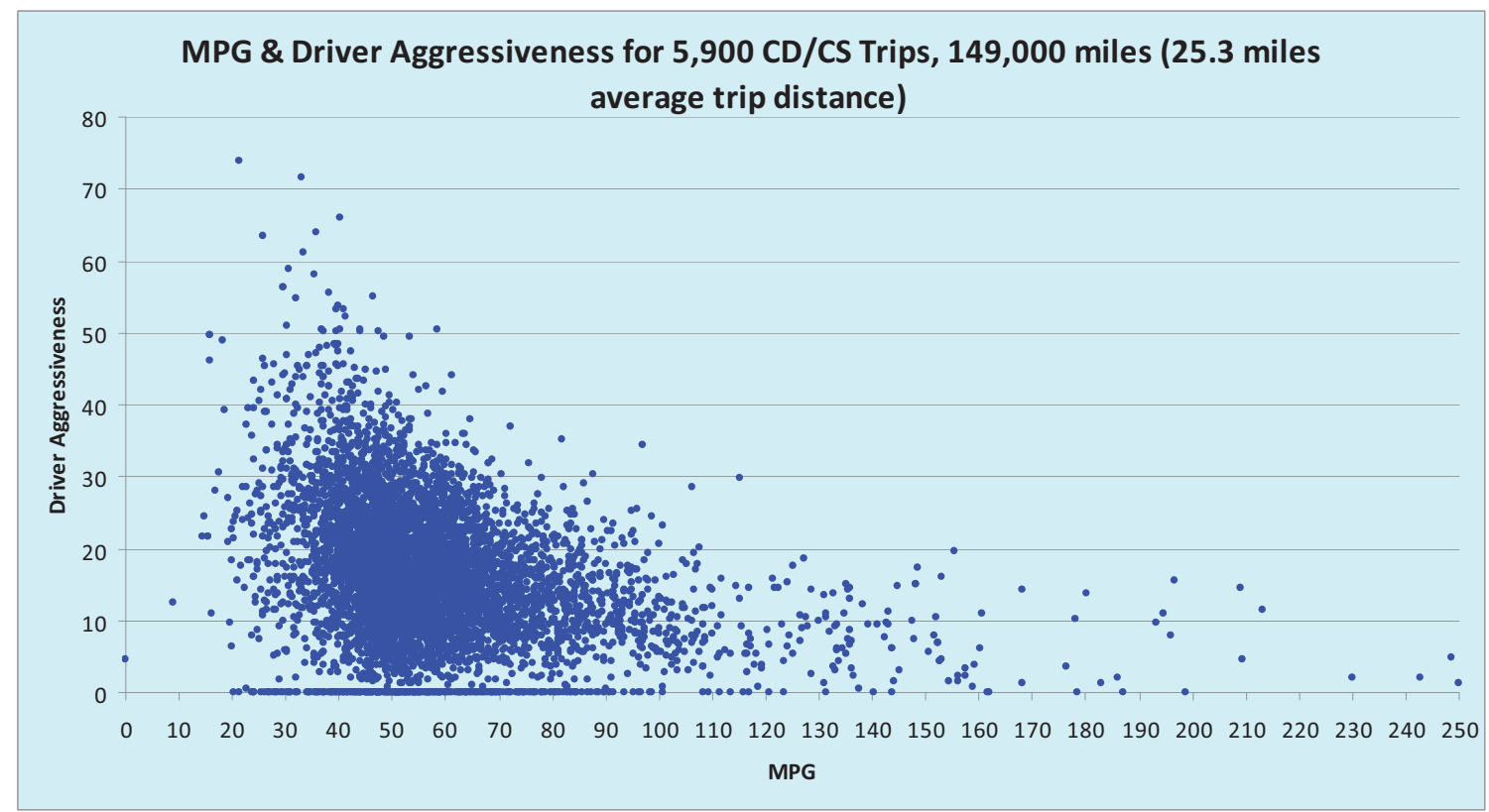

Figure D-2. Driver aggressiveness impacts on mpg for 5,900 trips driven 149,000 miles in mixed charge-depleting/charge-sustaining mode for 141 Hymotion Prius PHEV conversions. The one $0 \mathrm{mpg}$ result in the graph along the left axis is for a trip in all-electric mode, finishing the trip on energy from the HEV battery. 


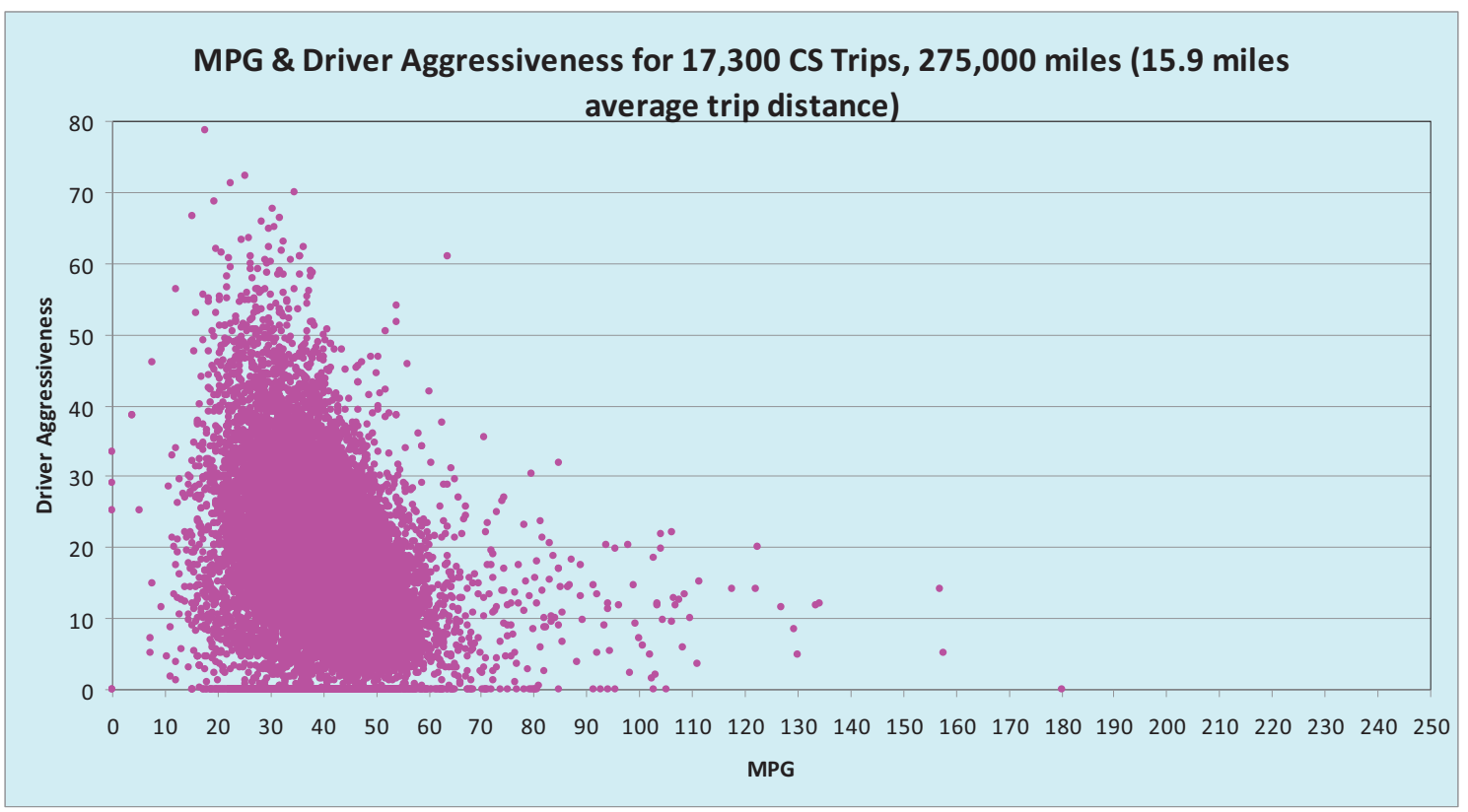

Figure D-3. Driver aggressiveness impacts on mpg for 17,300 trips driven 275,000 miles in charge-sustaining mode for 141 Hymotion Prius PHEV conversions. The four 0 mpg results in the graph along the left axis are for trips in all-electric mode, starting and finishing the trip on energy from the HEV battery. 
Appendix E

Miles per Gallon and Operating Mode Trends 


\section{Appendix E - Miles per Gallon and Operating Mode Trends}

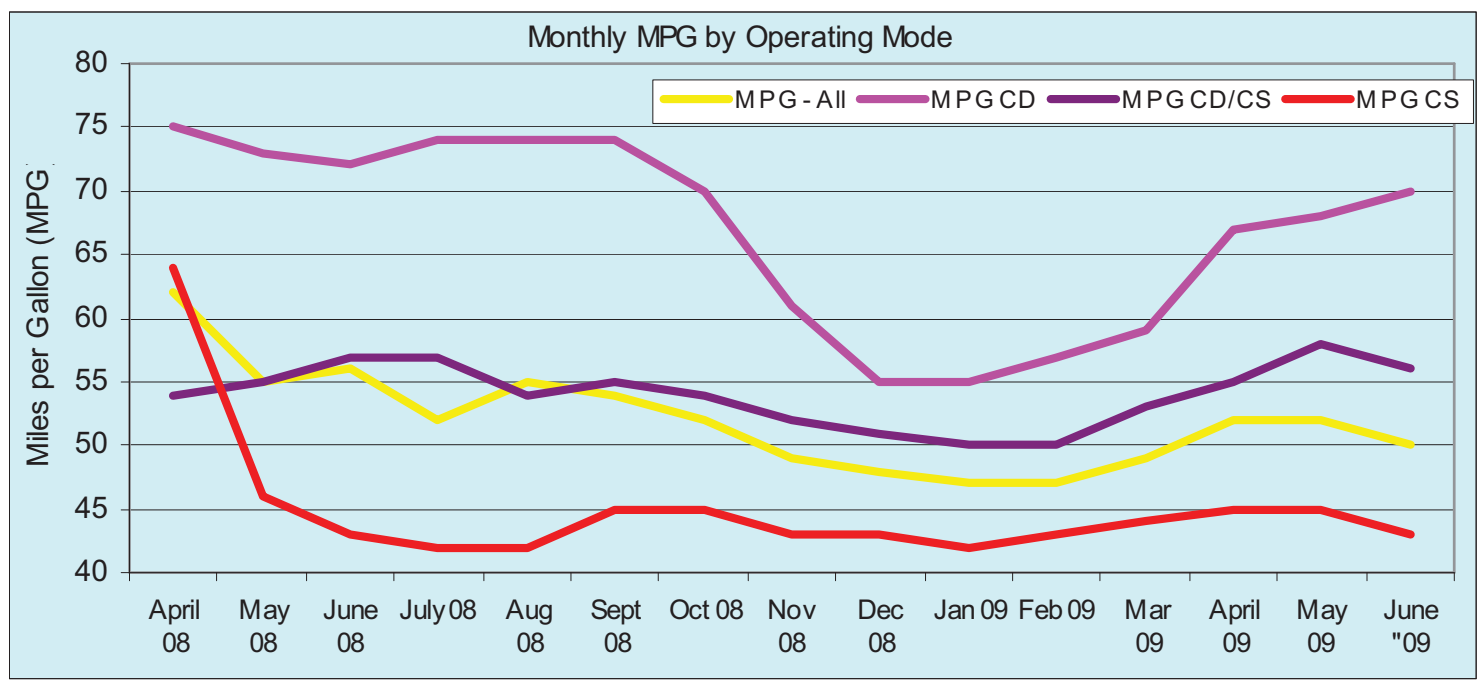

Figure E-1. Miles per gallon monthly results by operating modes.

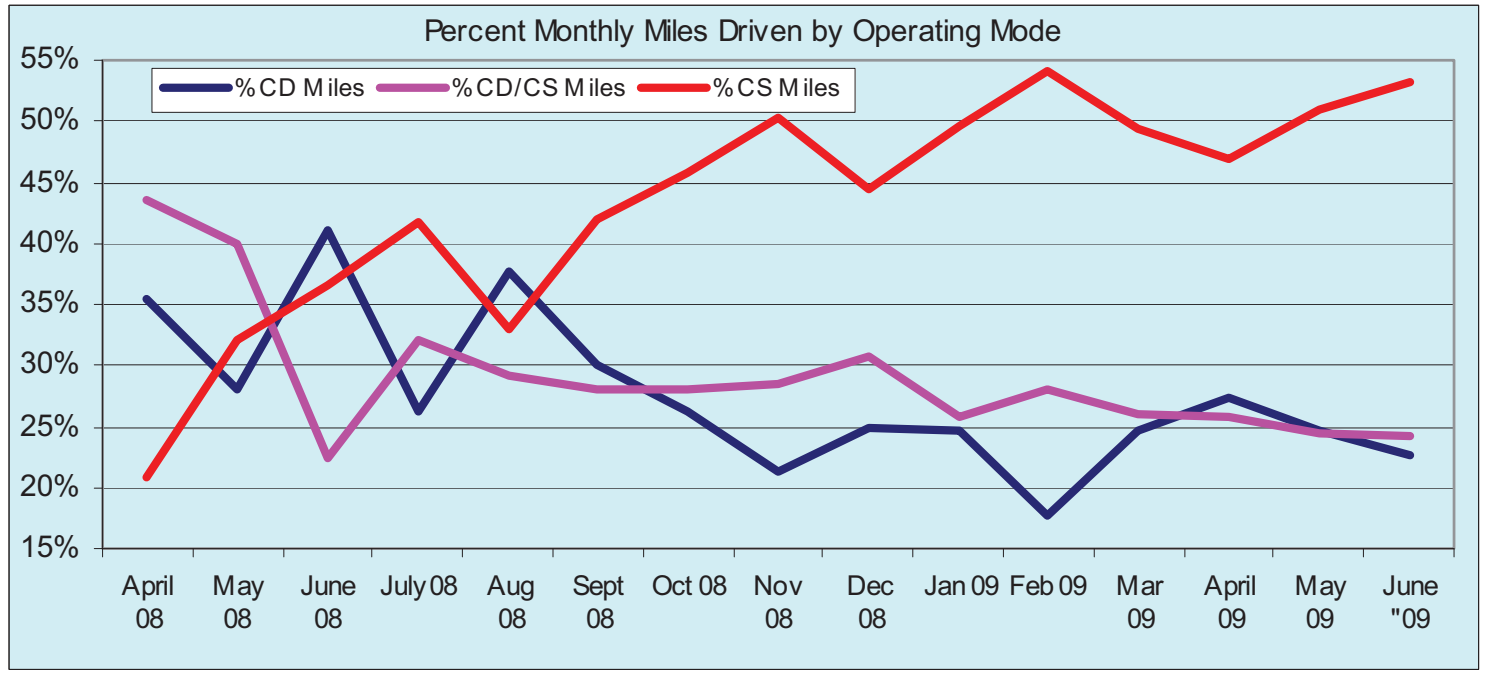

Figure E-2. Percentage of monthly miles driven by operating mode. 


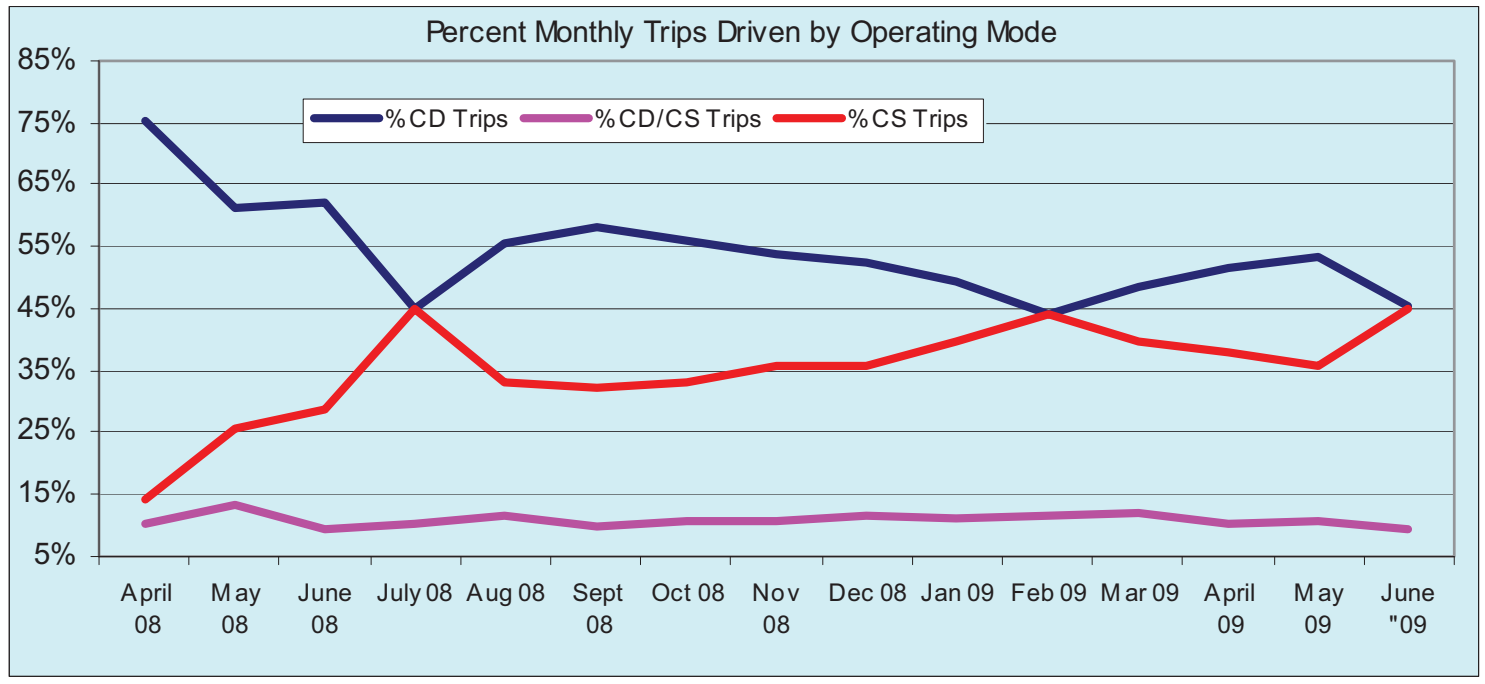

Figure E-3. Percentage of monthly trips taken by operating mode. 
Appendix F

EV1 EVAmerica Fact Sheet 


\section{Appendix F - EV1 EVAmerica Fact Sheet}

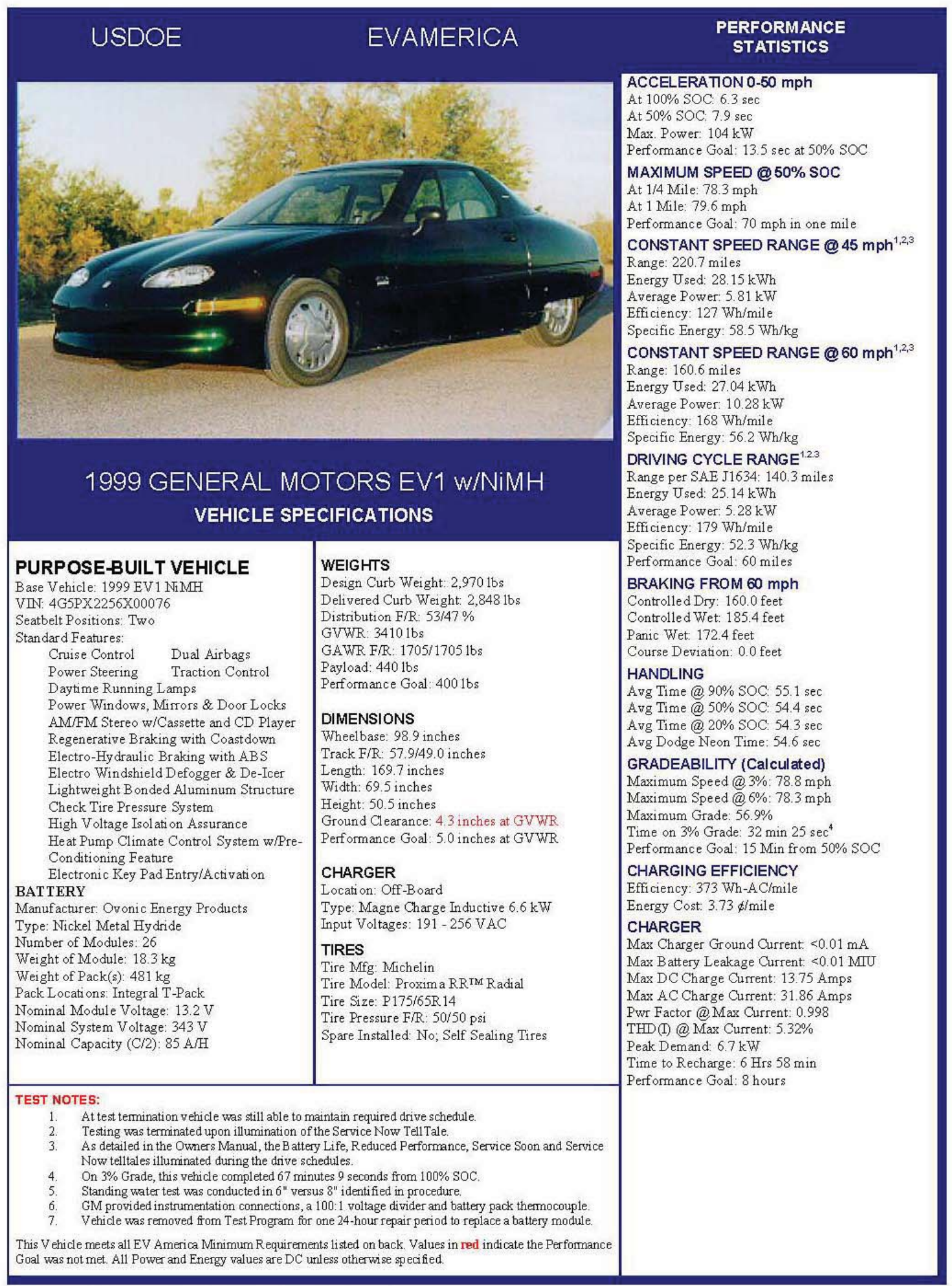

C1999 Electric Transportation Applications All Rights Reserved 